\title{
AN ADVANCED MODELING SYSTEM FOR OPTIMIZATION OF WIND FARM LAYOUT AND WIND TURBINE SIZING USING A MULTI-LEVEL EXTENDED PATTERN SEARCH ALGORITHM
}

\author{
Bryony DuPont ${ }^{1}$ \\ School of Mechanical, Industrial, \\ and Manufacturing Engineering \\ Oregon State University \\ Corvallis, OR 97331 \\ bryony.dupont@oregonstate.edu
}

\author{
Jonathan Cagan \\ Department of \\ Mechanical Engineering \\ Carnegie Mellon University \\ Pittsburgh, PA USA 15232 \\ cagan@cmu.edu
}

\author{
Patrick Moriarty \\ National Wind Technology Center \\ National Renewable Energy \\ Laboratory \\ Boulder, CO USA 80303 \\ patrick.moriarty@nrel.gov
}

\section{ABSTRACT}

This paper presents a system of modeling advances that can be applied in the computational optimization of wind farms. These modeling advances include accurate cost and power modeling, partial wake interaction, and the effects of varying atmospheric stability. To validate the use of this advanced modeling system, it is employed within an Extended Pattern Search (EPS)-Multi-Agent System (MAS) optimization approach, for multiple wind scenarios. The wind farm layout optimization problem involves optimizing the position and size of wind turbines such that the aerodynamic effects of upstream turbines are reduced, increasing the effective wind speed and resultant power at each turbine. The EPS-MAS optimization algorithm employs a profit objective, and an overarching search determines individual turbine positions, with a concurrent EPS-MAS determining the optimal hub height and rotor diameter for each turbine. Two wind cases are considered: (1) constant, unidirectional wind, and (2) three discrete wind speeds and varying wind directions, each of which having a probability of occurrence. Results show the advantages of applying the series of advanced models as compared to previous application of an EPS with less advanced models to wind farm layout optimization, and imply best practices for computational optimization of wind farms with improved accuracy.

Keywords: Wind Farm Optimization; Wind Farm Modeling; Extended Pattern Search Algorithm; Systems Optimization

\section{INTRODUCTION}

As the population of the world grows and fossil fuel-derived electricity continues to be a significant cause of greenhouse gas emissions, it is imperative that clean alternative energies such as wind power are thoroughly explored. Increasing the incorporation of wind power into the national power development scheme will help to fulfill the substantial growth in power the United States is projected to require - a 39\% increase over the next 20 years [1]. Additionally, the United States Department of Energy has presented the challenge to meet $20 \%$ of the U.S. total electricity demand using wind power by the year 2030 [1]. To meet this challenge, it will be increasingly important that newly developed wind farms are performing optimally, that is; they develop as much power as possible, while doing so at a reasonable cost. Other factors, such as local weather and topographical variation, must be considered in order to accurately predict wind farm performance prior to development, further breaking down barriers to implementation of establishing new wind farms. This creates an opportunity to apply computational optimization algorithms that incorporate state-of-the-art modeling of power and cost to the design of prospective U.S. wind farms.

Though there has been significant research to date in the field of computational optimization as applied to wind farms (particularly to wind farm layout, or micrositing), research has only begun to approach the problem with the goal of developing real-world applicable results. To approach this real- 
world applicability, this work proposes an advanced modeling system that is designed to be employed within wind farm optimization algorithms; these advances are a significant step forward from previous wind farm optimization literature in terms of model fidelity and inclusion. To utilize and validate the proposed advanced modeling system, it is employed within an improved Extended Pattern Search (EPS) algorithm, as the EPS has been successfully applied to wind farm micrositing optimization [2]. The advanced modeling system presented in this work includes:

a. $\quad$ A more accurate means of modeling cost, based on the NREL Wind Cost and Scaling Model [3][4], that estimates cost based on the parameters of turbine rotor radius and hub height.

b. The inclusion of wind shear (the variation of wind velocity with respect to height from the ground) in the calculation of effective wind speed and wake propagation.

c. The effects of atmospheric stability, considered in two ways: first, by accounting for the change in wind shear profile shape based on time of day and season, and second, by allowing variation in the wake decay constant based on atmospheric stability conditions, which is partially responsible for determining wake shape and wind speed deficit.

d. The consideration of partial wake interaction, which unlike many previous wind farm optimizations that treat turbine rotors as points, better represents overlapping wakes across the rotor swept area.

These models, employed collaboratively as part of the objective used in the EPS-MAS system, help advance the state-of-the-art of analytical modeling for wind farm optimization. Each of these models is considered to be more accurate and representative of real-world conditions that previous models used for wind farm optimization [2]. Therefore, it is assumed that the results developed through the application of the advanced modeling system (and layouts subsequently optimized using the EPS-MAS) presented in this work will better predict wind farm performance prior to wind farm installation.

Employing the advanced modeling system, the EPS within a multi-agent system (MAS) algorithm accounts for each turbine's design activities. The agent approach is advantageous given that it facilitates multiple objectives and its architecture is highly adaptable, such that agents can be removed, added, or manipulated easily, without altering other facets of the code [5]. This will be particularly beneficial considering proposed future EPS-MAS work, which will account for the dynamic nature of the wind farm layout problem as new technologies, turbine designs, and local environmental factors are considered.

Previous approaches to solving the wind farm optimization problem - specifically those that include modeling variation from traditional test cases - are presented, along with a discussion of both the traditional EPS and the Multi-Agent System approach utilized as a case study algorithm in this work. Next, the series of advanced models are presented - cost modeling, wake modeling, atmospheric stability, and power modeling. Then, the numerical procedure and formal methodology are shown, followed by results and discussion for both wind test cases.

\section{PREVIOUS APPROACHES}

Previous literature in wind farm layout optimization generally focuses on maximizing the power development of the farm while minimizing cost. The first computational optimization approach to the wind farm layout optimization problem was performed by Mosetti et al. in 1994 [6], who established the framework upon which many subsequent optimization schemes were based. Within a genetic algorithm (GA) approach, Mosetti et al. used chromosomal strings that represented turbine position to create a discretized grid solution space. Grady et al. [7] improved upon this work by exploiting greater computational resources, allowing their GA to give superior results. Both of these optimization methods utilized the 2-D PARK model developed by Jensen [8] and minimize the objective of total cost of the farm while simultaneously maximizing power development. 
As the most commonly utilized algorithm for the wind farm layout optimization problem, more advanced GA approaches have been widely applied, using a variety of objective functions and modeling approaches. A Distributed Genetic Algorithm (DGA) approach was developed by Huang [9]; while using the same discretized space and modeling as Mosetti et al. [6], the DGA was able to create layouts that develop more power, utilizing an objective function that maximized an estimate of wind farm profit. Huang then improved on the DGA by creating a Hybrid-DGA approach [10] that used both global and local objective functions. Wang et al. [11] developed a GA that improved on the discretization of previous work by allowing for varying shapes and coarseness of the solution space. Similar approaches were developed by Sisbot et al. [12] and Emami et al. [13], which expanded the use of GAs to solve the wind farm layout optimization problem by separating total farm cost and power development into distinct objectives, creating multi-objective optimizations that allow for focus on initial farm costs. SerranoGonzalez et al. [14] and Kusiak et al. [15] developed multi-objective evolutionary algorithm approaches (similar to a GA) that maximized the annual energy production of the farm; the latter created a more accurate measure of farm cost than cost modeling used in previous work. One shortcoming of these GA methods is the use of a discretized solution space, which limits the placement of turbines to defined cells, such that precise local placement is infeasible. Other researchers employing an evolutionary approach used heat-map style continuous space in order to enable more precise local placement [16].

In addition to genetic algorithms, multiple other methods have been used to solve the wind farm layout optimization problem. Particle swarm optimization algorithms are related to both biological swarming behaviors and evolutionary computation, and were used by Wan et al. $[17,18]$ and Chowdhury et al. [19] to solve the wind farm optimization problem. Ozturk et al. [20] developed a different approach, a heuristic method, that utilized a weighted multi-objective function. These algorithms include a significant advantage over traditional GAs in their use of a continuous solution space, which the EPSMAS also employs. Other algorithms applied to wind farm layout optimization include the simulated annealing work presented by Bilbao et al. [21], and the mixed-integer nonlinear discrete combinatorial optimization algorithm developed by Mustakerov et al. [22]. The Extended Pattern Search algorithm has also been successfully applied to wind farm layout optimization and has incorporated multiple advances in modeling that enable the development of more real-world applicable wind farm layouts, as introduced in this work and published in $[2,23]$.

There are several recent works that seek to expand on the capability of various algorithms such that state-of-the-art modeling of cost, wake interaction, and power are incorporated into the optimization. Zhang et al. [24] created a cost surface to more accurately estimate the costs associated with wind farm development. Chowdhury et al. [25] established a framework for the selection of turbines with varying rotor radii, and DuPont and Cagan [23] expanded that capability by enabling an EPS algorithm to select both turbine hub heights and rotor radii. Benatiallah et al. [26] used actual long-term wind data as an input to their genetic algorithm for wind farm layout. Chen et al. [27] explored the implications of landowner decisions on resulting farm layouts. Kusiak et al. [15] used preliminary data mining in conjunction with a GA to determine the optimal control settings for a proposed farm. Kwong et al. explored wind farm layout optimization that considers noise propagation and limiting [28]. More recent work by Chowdhury et al. [29] used a Kernel Density Estimation to better model multi-modal wind data. A large research collaborative (including Riso National Laboratory and multiple industry partners) have recently explored wind farm optimization while considering both optimal power development and the interrelated effects of turbine loading characteristics [30]. These advances suggest that it is not only the choice and development of the optimization algorithm itself, but also the advances in how we model wind farm optimization that will lead to robust and thoroughly tested proposed layouts that perform as predicted.

The current work builds on previous Extended Pattern Search research that has been applied to the wind farm layout optimization problem with success by DuPont and Cagan [2]. The previous application of EPS indicated that the combination of deterministic search and stochastic elements characteristic of the EPS were particularly well-suited to the multi-modal wind farm layout problem, allowing for the development of superior layouts than previous algorithms, including comparable genetic algorithms. 
As the efficacy of the EPS as applied to wind farm layout optimization has been proven, focus has shifted toward incorporating advanced modeling into the optimization, which will be discussed in the following sections. Advancing the modeling used in wind farm optimization will enable the EPS to develop layouts whose performance is representative of actual onshore wind farms.

\section{MULTI-LEVEL EXTENDED PATTERN SEARCH}

The proposed advanced modeling system is employed within an improved version of the established EPS algorithm for wind farm layout optimization developed by DuPont and Cagan [2]. A pattern search is a purely deterministic search algorithm [31] that traverses potential solutions using a defined series of pattern directions. The search only allows each turbine agent to accept solutions for which there is a benefit to the objective evaluation. The extensions that give the EPS its name are attributes that infuse stochasticity into the search, aiding in escaping local minima. Multiple stochastic extensions are used throughout the EPS. First, a randomized initial layout of turbines is used in order to establish a broad range of turbine locations while not explicitly assigning starting locations. Secondly, the search order is randomized such that no turbine's individual movement is favored over another. Thirdly, a popping algorithm is employed that will select the weakest turbines (based on power development) and attempt to assign them to a new random location, until a certain number of attempts are made or the turbine is relocated with a superior global evaluation. It has been shown that the EPS is well-suited to complex layouts problems [32], particularly the wind farm layout optimization problem where it performs better than comparable genetic algorithms [2].

In order to accommodate advances in modeling and to enhance algorithm capability, this work explores a multi-level EPS - the primary EPS searches through turbine locations on a defined continuous solution space, while two secondary concurrent EPS algorithms search through varying hub heights and rotor diameters in order to select optimal individual turbine geometries. This allows the benefits of the EPS to be extended to both the wind farm micrositing problem and turbine sizing optimization. A flowchart depicting the basics of the multi-level EPS is included in Fig. 1.

A set of four pattern search directions is followed for each individual EPS. For the location search, the pattern directions are $(+x,+y,-x,-y)$ in the $x-y$ solution space. For each of the sub-level searches, the pattern directions are $(+\mathrm{L},-\mathrm{L},+\mathrm{L} / 2,-\mathrm{L} / 2)$, where $\mathrm{L}$ represents a length in meters, either changing the height of the hub of the turbine in the z-direction or the radius of the rotor. At the start of each search, the pattern directions are traversed at a given step size, which is halved after no further movements are selected for that step size. The search exits after a minimum step size is reached, allowing the turbine agents to select both precise coordinates and geometries.

\section{MULTI-AGENT SYSTEM METHODOLOGY}

A multi-agent system (MAS) is a collaboration of semi-autonomous software agents, loosely simulating the function of a human design team. Each agent represents a single purpose or specialty just as a single design engineer would have unique training or experience. Individually, agents work internally to meet their own particular goals and job function. However, if given the means to communicate effectively within a group, a multi-agent system can interconnect and collectively work towards a balance between the global optimum and their individual objectives. The agents in the current system, which are both autonomous and capable of collaboration, are called collaborative agents [33]. The solutions acquired by collaborative agents may be superior than the sum of the capabilities of the individual agents involved [34]. The cooperation of agents representing strategies and capabilities grouped together in multi-agent systems has been shown to be very successful in solving engineering design problems in previous systems, such as A-Teams [35], A-Design [36], and blackboard systems [37].

In the current work, an individual agent represents a single turbine. The agent is equipped with memory capability for its current location, previous location, current and most recent previous geometric parameters, and current upstream and downstream turbines. An initial number of agents are created, with additional individual turbine agents added to determine layouts with the optimal number of turbines. The 
EPS performs on one agent at a time, with each agent concurrently selecting its new potential locations, potential new hub height and rotor radius. Then, each agent calculates the global objective, and determines whether to take a potential move or to take on new sizing. Once an agent has completed a single round of the EPS-MAS, a new agent begins. The order in which the agents perform the EPS-MAS is randomized, which is one of the beneficial extensions of the EPS-MAS.

The benefit of using MAS architecture is that it facilitates future alterations in coding, which is imperative for applying the EPS-MAS to wind farm optimization, as advances in modeling and methodology are currently being undertaken by many researchers and are being updated rapidly. Additionally, the use of the MAS increases algorithm efficiency by restricting the size of the optimization search tree, as each turbine agent retains and updates information about neighboring turbines, as opposed to re-evaluating the entire field at every iteration.

\section{ADVANCED MODELING 5.1 COST MODELING}

Accurately estimating the cost of installation of an onshore wind farm is a complex task that requires the consideration of a large number of variables, including the material and manufacturing costs for each turbine, land lease costs, infrastructure and electrical connectivity costs, and many others. The National Renewable Energy Laboratory (NREL) developed a tool to estimate the costs associated with installation and operation and maintenance of wind farms, with projection capability for turbines of varying sizes and future installations [4]. This cost model is embedded in a spreadsheet as part of the Jobs and Economic Development Impact (JEDI) model for wind power that predicts the cost of turbines based on a series of user-configurable parameters [3]. Though the JEDI tool is not intended to predict the actual price of turbines (as the market and is highly variable), we use this work as a means to estimate the cost of the individual turbines on the farm such that the global objective function can minimize overall costs.

Using the coupled input data of rotor radii (between $19 \mathrm{~m}$ and $56 \mathrm{~m}$ ) and the effective wind speed compensated for hub height using the power law of Eq. (9) (between $38 \mathrm{~m}$ and $138 \mathrm{~m}$ ), power is estimated using Eq. (11). These resulting calculated power evaluations are then used as input into the JEDI model for an individual turbine. The project cost results are used to create a $2^{\text {nd }}$-order polynomial surface [23] that is dependent on rotor radius and hub height, as shown in Fig. 2.

32 The cost surface (as a function of radius and hub height) depicted in Fig. 2 is estimated by Eq.(1):

$C(r, h)=(2.454 e+06)-(2.161 e+05) r-(1.203 e+04) h+6039 r r^{2}+2455 r h-161.2 h^{2}$

Compared to the cost modeling used in previous work [6,7] which was based solely on the number of turbines in each potential farm installation, the use of the NREL JEDI-derived cost surface is much more accurate and representative of real-world farm costs.

\subsection{WAKE MODELING AND PARTIAL WAKE INTERACTION}

In order to determine the amount of power a turbine is capable of developing, a 3-D extrapolation of the PARK wake model is used [8]. This wake model is a simplification of the complex aerodynamics involved with the motion of turbine blades rotating through air. This rotation causes a wake - an assumed conical-shaped area of air in which the flow is severely decremented immediately behind the rotor, but asymptotically approaches the ambient wind speed downstream. The PARK model is included in this work for multiple reasons: (1) it is commonly employed in wind farm optimization research, as its simplicity lends to fast processing for highly iterative optimization methods, (2) it has been shown to reasonably approximate wind farm flow as compared to other models, particularly for turbines in very few wakes [38], and (3) suggested uncertainty or over-prediction of power losses by the PARK model for 
large wind farms [39] are not impactful, as the optimization method uses relative variation in power development between solutions - and not a global power threshold - to determine optimality. This wake is modeled as a triangular footprint in two dimensions, with both the width of the wake and the wind speed deficit being proportional to the distance downstream from the rotor [2]. The 3-D extrapolation of the PARK wake model is shown in Fig. 3.

In Fig. $3, U_{0}$ is the ambient wind speed, $r_{\mathrm{r}}$ is the radius of the turbine rotor, $r_{1}$ is the radial width of the wake at distance $x$ downstream from the turbine, $v$ is the reduced velocity directly behind the turbine, and $U$ is the wind speed within the wake at distance downstream. $U$ is a decremented representation of $U_{0}$ and is abstracted to be constant across the width of the wake (for the same value of $y$ ). The formula for $U$, the downstream wind speed within the wake, is given by:

$$
U=U_{0}\left(1-\frac{2}{3}\left(\frac{r_{r}}{r_{r}+k y}\right)^{2}\right)
$$

Equation (2) is used to determine the effective wind speed for any turbine that lies within one wake, where $k$ is the wake decay constant as a function of height and stability conditions, as shown in Eq. (10).

A turbine that does not lie within a wake of an upstream turbine has an effective wind speed equal to the ambient wind speed approaching the farm. In the case of a turbine located in multiple wakes, it is necessary to sum the individual kinetic energy deficits of each of the $n$ wakes to calculate the effective wind speed, as given by:

$$
U=U_{0}\left[1-\sqrt{\sum_{i=1}^{n}\left(1-\frac{U_{i}}{U_{0}}\right)^{2}}\right]
$$

The width of a wake is proportional to the downstream distance from the wake-producing turbine, based on the rotor radius:

$$
r_{1}=r_{r}+k y
$$

Two partial wake interaction scenarios are considered. The first is a turbine rotor that is partially located within the wake of one upstream turbine, or two upstream turbines whose wakes do not overlap across the rotor swept area. These scenarios are depicted in Fig. 4.

In either of these cases, the search algorithm determines if the turbine rotor has a partially interacting wake by calculating the distance between the hub of the turbine in question and the centerline of the wake:

$$
d_{r-w}=\sqrt{\left(x_{t}-x_{w}\right)^{2}+\left(z_{t}-z_{w}\right)^{2}}
$$

where $x_{\mathrm{t}}$ and $z_{\mathrm{t}}$ are the $x$ - and $z$-coordinates of the turbine hub, and $x_{\mathrm{w}}$ and $z_{\mathrm{w}}$ are the $x$-and $z$-coordinates of the centerline of wake at downstream distance y. Using Eq.(4), the radius of the wake $r_{\mathrm{w}}$ at the given downstream distance $y$ can be calculated. Partial wake interaction can be verified using the following statements:

$$
\left\{\begin{array}{l}
d_{r-w} \geq r_{r}+r_{w} \quad \text { Wake does not act on rotor swept area. } \\
d_{r-w}<r_{r}+r_{w} \quad \text { Wake acts on portion of rotor swept area. }
\end{array}\right.
$$


Once partial wake interaction is verified, the formula for circle-circle intersection is used to calculate the area of the partial wake:

$$
\begin{aligned}
& A_{\text {Overlap }}= \\
& r_{r}^{2} \cos ^{-1}\left(\frac{d_{r-w}^{2}+r_{r}^{2}-r_{w}^{2}}{2 d_{r-w} r_{r}}\right)+r_{w}^{2} \cos ^{-1}\left(\frac{d_{r-w}^{2}+r_{w}^{2}-r_{r}^{2}}{2 d_{r-w} r_{w}}\right)- \\
& \frac{1}{2} \sqrt{\left(-d_{r-w}+r_{r}+r_{w}\right)\left(-d_{r-w}+r_{r}-r_{w}\right)\left(-d_{r-w}-r_{r}+r_{w}\right)\left(d_{r-w}+r_{r}+r_{w}\right)}
\end{aligned}
$$

With the area of the acting wake(s), one can determine the percentage of the rotor swept area that is affected by the wake(s):

$$
\%=\frac{A_{\text {Overlap }}}{\pi r_{r}^{2}}
$$

With this percentage calculated, the effective wind speed is then determined for the areas that are affected by a wake or wakes using Eq. (2), and the effective wind speed is multiplied by the percentage(s) of overlap. The remaining portion of the rotor swept area is multiplied by the ambient wind speed, and these values are summed to determine the total estimated effective wind speed for the turbine.

The second wake scenario is that of a turbine that is in two or more wakes that overlap across the rotor swept area, as depicted in Fig. 5.

The percentage of wake overlap as depicted in Fig. 5 is not trivial to calculate, and as such determining the areas of overlap is calculated by applying a discretized mesh on the rotor swept area. The discretization includes 49 points, which represent an evenly-spaced grid with a coarseness of $1 / 4$ rotor radius. At each of the discretized points, the effective wind speed can be calculated directly by determining whether the point lies within an upstream wake or wakes. If a discrete point of the rotor swept area lies within the wake of the upstream turbine in question, then the effective wind speed at that point can be calculated using Eq. (2). This process is repeated for each of the 49 discrete points, and the effective wind speed is calculated based on the distance from, and the effective wind speed at, the upstream turbine(s) for each point. Each point then contributes 1/49th of the total effective wind speed for the turbine.

It should be noted that this wake model is an idealized semblance of the wake profile and behavior [40]. In particular, the wind speeds within a wake are considered constant across the width of the wake for a given downstream distance, whereas the lines of constant wind speed taking on the shape of a Gaussian distribution would be more accurate. Similarly, there is an "on/off" characteristic of the wake boundary that belies the more realistic wind speed gradient at the edges. Additionally, this model cannot account for the complex turbulent flow directly behind and caused by the rotor blades, and as such the wake effects of the near-wake region are unrealistic. However, given the minimum proximity constraint between turbines, this shortcoming does not significantly affect the optimization. Regardless of these simplifications, the use of 3-D wake modeling improves upon previous wind farm optimization approaches that only utilize a 2-D representation of the wake and only consider turbines as point coordinates.

\subsection{ATMOSPHERIC STABILITY}

The atmospheric boundary layer, the portion of the atmosphere that is closest to the earth's surface and the region in which most wind turbines are located, has physical attributes (temperature, wind direction, humidity, etc.) that can vary across the vertical range of a farm site and can impact wind turbine 
power development. The effects of temperature on airflow caused by the sun determine the stability of the atmospheric boundary layer, cycling through stability conditions based on the time of day. Stable conditions occur when the temperature increases with height, often at night [41]. In the daytime, however, heat from the sun warms the ground and subsequently the air near the ground, creating unstable atmospheric conditions. This behavior creates significant atmospheric mixing that change the wind velocity and temperature gradients. Neutral stability conditions occur during the transition periods between stable and unstable.

The potential high turbulence in unstable conditions can cause rotor fatigue and early turbine failure [42]. Stable atmospheric conditions have the highest wind shear, and, depending on wind speed and turbine size, may prove to either increase or decrease the rotor-averaged effective wind speed [43]. Frandsen et al. [44] proposed that the effects of changes in atmospheric stability can greatly impact wind farm performance, including altering wind speed and turbulence. Work by Irwin [45], Hanafusa et al. [46], and Zoumakis et al. [47] explored how atmospheric stability and surface roughness affect the wind profile power-law exponent. Sumner and Masson [48] concluded that improper accounting for atmospheric stability using point estimations of the wind accounts for a 5\% overestimation of the wind capacity of a site. Wharton and Lundquist [43] used SODAR and cup anemometer measurements to define how the shape of the power law profile changes with atmospheric stability based on season.

In the current work, changes in atmospheric stability conditions are mathematically represented through two means. First, stability variations are reflected in vertical wind shear profile shape, that is, the curvature of the boundary layer flow that dictates the growth in wind speed with height from the ground. The second means is through variation in the wake decay constant, a value that aids in determining wake propagation width and wind speed recovery within a wake.

A rotor that is positioned at a higher hub height will generally see higher wind speeds, based on the influence of the boundary layer fluid flow, which is known as vertical wind shear and is represented by the power law [49]:

where $\mathrm{U}(\mathrm{Z})$ is the wind speed at hub height $\mathrm{z}, \mathrm{U}\left(\mathrm{Z}_{\mathrm{r}}\right)$ is the wind speed at a reference hub height $\mathrm{z}_{\mathrm{r}}$. The power law exponent $\alpha_{\mathrm{h}}$ varies with time of day, season, mixing parameters and other factors. In the current work, atmospheric stability is accounted for by averaging yearly power law exponent data from the Lamar Low-Level Jet Program (LLLJP) [50], where $\alpha_{\mathrm{h}}=0$ implies no shear across the rotor swept area and $\alpha_{\mathrm{h}}=0.3$ represents a very large shear. The average value for heights of 3 meters to 113 meters over the entire year is $\alpha_{\mathrm{h}}=0.15567$. The resulting wind shear profiles for stable, neutral, and unstable atmospheric conditions are shown in Fig. 6.

It should be noted that this work does not strive to show whether low or high shear flow is optimal for turbine power development; rather we seek to enable wind farm optimization algorithms to consider these effects, and to explore how wind farm power development varies with shear condition, and its dependence on wind speed, turbine size, and farm location.

The second means of incorporating atmospheric stability conditions into wind farm optimization downstream that the wind speed within a wake recovers, as well as helping to determine the width of downstream wakes (as formulated in Eq. (2) and Eq. (4)). As such, variation in the wake decay constant due to atmospheric stability can have a significant effect on the power development of wind turbines. In this work, we model the wake decay constant as a function of height and atmospheric stability conditions. This model is derived from the turbulence intensity reported from the LLLJP [50], and the estimation of wake decay constant being equal to roughly half the value of the turbulence intensity [51]. Additionally, 
we employ the approximate 20/40/40 ratio of neutral/stable/unstable conditions seen for the Lamar wind site from which the turbulence intensity data is drawn [52]. This estimation allows us to understand how changes in atmospheric stability relatively affect optimal layouts and turbine sizing as conditions change between potential sites. The effect on wake width caused by variation in wake decay constant $(k)$ for stable, unstable, and neutral conditions is depicted in Fig. 7. The formulas derived for variation in wake decay constant for each atmospheric stability condition as a function of height (from LLLJP data [50]) are given in Eq. (10):

neutral: $k=0.088 h^{-0.152}$
unstable: $k=0.098 h^{-0.135}$

In this work, atmospheric stability is explored through the development of three optimized layouts for each wind case, each representing stable, neutral, and unstable atmospheric stability conditions. Neutral atmospheric conditions are represented using an average yearly power law exponent based on wind data from the LLLJP $(\alpha h=0.15567)$; unstable atmospheric conditions are represented using a low power law exponent $\left(\alpha_{\mathrm{h}}=0.1\right)$; and stable atmospheric conditions are represented using a higher power law exponent $\left(\alpha_{\mathrm{h}}=0.2\right)$. Traditionally, a constant power law exponent value of $\alpha_{\mathrm{h}}=0.14$ is used, derived from flow over flat plates [49]. The wake decay constant as a function of height is calculated for each of the three atmospheric stability conditions as stated in Eq. (10). These results will explore how the change in the wind shear profile shape and wake propagation affects the resulting layout and turbine sizing optimization, and offer insight into the effects of using more site-accurate power law profile exponents and wake decay constants.

\subsection{POWER MODELING}

Accurately reflecting the power production of a hypothetical wind farm is imperative in order to validate the results of a wind farm layout optimization. This work uses power modeling that accounts for turbines of varying geometries, and as such employs power modeling given by Manwell et al. [49]:

$$
P=\frac{1}{2} \rho A U^{3} C_{P}
$$

where $\rho$ is the density of air (considered constant at $1.225 \mathrm{~kg} / \mathrm{m}^{3}$ ), $A$ is the cross-sectional area swept by the rotor blades, $U$ is the effective wind speed, and $C_{\mathrm{p}}$ is the power coefficient (which is relevant in the cubic region of the power curve shown in Fig. 8). The total power development of the farm is taken as the sum of the individual power outputs of each turbine. Additionally, a power curve was enforced to more realistically represent the capability for turbines to develop power, as shown in Fig. 8.

It should be noted that this algorithm deliberately allows for the selection of turbine geometries on a continuous scale; that is, virtually any discrete corresponding values of rotor radius and hub height can be chosen. Turbine manufacturers, however, generally produce turbine families that use a set of available geometries, and are not as widely variable as those used in this study. The hub heights and rotor diameters in this work are constrained to prevent infeasible combinations of these parameters.

The total project cost of the farm is taken as the sum of the project costs of each individual turbine as calculated by Eq. (1). The total power development of the farm is the sum of the individual turbine power outputs, as calculated in Eq. (11). With these two values, a global objective function is developed in order to accurately portray the interests of farm developers and researchers. This objective is the maximization of profit in dollars, formulated as the minimization of negative profit: 
where Cost $_{O \& M}$ is the annual operations and maintenance cost of the farm in $\$ /$ year, $t$ is the amount of time (years) over which the cost is relevant, $C_{\mathrm{F}}$ is the capacity factor at which the farm performs, and $C O E$ is the cost of energy - the price at which a farm owner may sell the energy their farm develops, in $\$ / \mathrm{kWh}$. The operations and maintenance costs are estimated to be [4]:

$$
\text { Cost }_{O \& M}=0.007 \times \text { Energy }_{\text {Yearly }} \times t \times C_{F} \times C O E
$$

The costs included are the initial project cost, which is generated by the cost surface given in Eq. (1), and the operations and maintenance costs per year, which are a function of the annual energy production of the farm (the amount of power the farm can produce per year). The annual energy production multiplied by the price at which the power can be sold in $\$ / \mathrm{kWh}$ gives the amount of money the farm can make.

\section{NUMERICAL PROCEDURE}

Two test cases are explored in this work, and are shown in Fig. 9. First, Case (a) is that of constant wind speed $(10 \mathrm{~m} / \mathrm{s})$ and unidirectional wind (from the bottom of the field in the $+y$ direction). Case (b) is a more accurate representation of wind site conditions, with three wind speeds $(6,9$, and 12 $\mathrm{m} / \mathrm{s})$ and thirty-six wind directions $\left(360^{\circ}\right.$ in $10^{\circ}$ increments), with a probability of occurrence for each, depicted as a bar graph in Fig. 10 [23]. These test cases are chosen due their popularity in wind farm optimization literature [2,6,7], and enable the application of the advanced modeling system presented in this work within new optimization algorithms frameworks; these test cases are widely available for testing algorithm efficacy.

The farm site is $2000 \mathrm{~m}$ x $2000 \mathrm{~m}$ with no topographical variation. The turbine size is initialized to an $80 \mathrm{~m}$ hub height with an $80 \mathrm{~m}$ rotor diameter. The EPS-MAS uses a continuous solution space, and as such every potential agent move first performs an interference check to ensure that it is not within 200 $\mathrm{m}$ radially of any other agent. Additionally, no agent is permitted to move itself out of the bounds of the farm area. After a random initial placement, a check is performed to validate whether an agent lies in the wake of its potential upstream turbines, and the percentage of the wake overlap. The agent then stores this information in order to calculate its own effective wind speed and power development. The initial step size of the coordinate EPS is chosen is $400 \mathrm{~m}$ and is halved until reaching a minimum value of $6.25 \mathrm{~m}$. The sub-level Hub Height EPS algorithm uses an initial step size of $45 \mathrm{~m}$, and is halved until reaching a minimum value of $1.4 \mathrm{~m}$. The sub-level Rotor Radius EPS algorithm uses an initial step size of $25 \mathrm{~m}$, and is halved until reaching a minimum value of $1.5 \mathrm{~m}$. Feasible hub height values are between $38 \mathrm{~m}$ and 135 $\mathrm{m}$, and feasible rotor radii are between $19 \mathrm{~m}$ and $67 \mathrm{~m}$. The popping algorithm will attempt to relocate the 10 worst performing turbines up to 100 random locations. The cost of energy is taken to be $0.1 \$ / \mathrm{kWh}$ [9].

\section{RESULTS}

For both the unidirectional wind case (Case (a)) and the more realistic multidirectional wind case with varying wind speeds (Case (b)), three atmospheric conditions are represented. The values for the power law exponent and the wake decay constant as they vary for each wind condition are given in Table 1. Two sets of results are shown for each wind case: the first includes variation in only the power law exponent $\alpha_{h}$, and the second includes variation in both the power law exponent $\alpha_{h}$ and the wake decay 
constant $k$. This approach will reveal more detail about how the changes in the wind shear exponent and wake decay constant can affect the optimal layout and turbine sizing of a proposed wind farm site.

A preliminary parametric optimization was conducted in order to determine the optimal number of years over which the objective should be considered [23]. As a result of this parametric optimization, subsequent use of the profit objective will be considered over a 20 -year farm life.

\subsection{Unidirectional Case}

Evaluating the objective for the unidirectional, constant wind speed case, the ambient wind speed is taken to be $10 \mathrm{~m} / \mathrm{s}$. Using this simplified wind case helps explore the capability of the algorithm, and gives a clear understanding of how the attributes of the search affect the result. For each stability condition, resulting layouts of 5-50 turbines were generated. The objective function evaluation data were then plotted versus the number of turbines, and a cubic polynomial fit was applied; the minimum value for each curve is taken to be the optimal number of turbines for each stability condition (similar to the procedure performed in previous EPS work [2]). Table 2 and Table 3show a comparison between the unidirectional case results for each of the three stability conditions, the first for variation in only the power law exponent, and the second for variation in both the power law exponent and the wake decay constant. A key to aid in interpretation of turbine sizes is given in Fig. 11 (these symbols indicate ranges but each turbine's size is exact). Fig. 12 includes the layouts for unstable atmospheric conditions, Fig. 13 for neutral conditions, and Fig. 14 for stable conditions.

These results show some interesting differences in layout with the varying atmospheric stability conditions. First, considering only the variation on the power law exponent, the lower $\alpha_{h}$ value influences optimal layouts with a greater number of turbines, but these turbines are generally smaller. The highest $\alpha_{h}$ value of 0.2 (corresponding to stable conditions) gives a layout with fewer turbines, but of significantly taller average turbine size. These results are consistent with our understanding of how the wind shear exponent influences the breadth of wind speeds. The ambient wind speed $(10 \mathrm{~m} / \mathrm{s})$ is lower than, but close to the reference wind speed $(11.5 \mathrm{~m} / \mathrm{s})$ for the power law calculation given in Eq. (9). This was deliberate to explore the incentive for turbines to increase their height or the size of their rotor swept areas, as doing so can result in an increase in power development, but will increase cost, potentially leading to an inferior objective evaluation. For all of the $\alpha_{h}$ values shown here, the largest possible turbine geometries were situated in the front of the field, with unobstructed ambient wind, where downstream turbines would select generally smaller geometries or taller hub heights to avoid placement within upstream wakes. It must also be considered that turbine agents have selected relatively small turbine geometries due to the trade-off between cost and size. This also indicates the influence of including partial wake interaction - the smaller the rotor swept area, the less likely a turbine will produce a wake large enough to encompass others, and the less likely it will be located within a wake itself.

The results that include variation in both the power law exponent and the wake decay constant indicate different optimization behavior than when only considering the power law exponent alone. Now, with additionally varying the wake decay constant, the clear relationship between atmospheric stability conditions and the incentive to gain height is less obvious. In fact, for all three conditions, the turbine geometries are quite similar. However, the results remain consistent in that the objective function evaluation and total power development were superior for stable atmospheric conditions, and less so for unstable conditions.

\subsection{Multidirectional Case}

As with unidirectional case, the multidirectional results are given for both considering only

variation in the power law exponent, and for variation in both the power law exponent and the wake decay constant. The results for variation in only the power law exponent are summarized in Table 4, with 
$\alpha_{h}=0.1$ (unstable), $\alpha_{h}=0.15567$ (neutral), and $\alpha_{h}=0.2$ (stable) now used within the multidirectional variable wind speed case. The results for variation in both the power law exponent and wake decay constant are summarized in Table 5. Resulting layouts for unstable, neutral, and stable conditions for both sets of considered variables are shown in Fig. 15, Fig. 16, and Fig. 17, respectively. The key for turbine geometries from Fig. 11 is applicable to the multidirectional layouts as well.

The results for the multi-directional, varying wind speed case show consistency with previous work [2] in that the turbine agents (as the full rotation of wind directions doesn't enable movement outside of wakes) tend to be fewer in number, maximize their downstream distance, and migrate toward the outer field perimeter. Therefore, the reduced wind speed behind a rotor is given the distance needed to recover and approach its ambient speed. This behavior is especially evident in the layouts where only variation in the power law exponent is considered. As with the unidirectional case, the higher $\alpha_{h}=0.2$ value suggests larger turbine geometries, and the smaller $\alpha_{h}=0.1$ value influences a layout of smaller turbine geometries. This is due to the effect of the power law exponent on the wind shear profile shape the larger exponent creates a more severe profile curve, with lower wind speeds at the ground and higher wind speeds at the top of the profile. The larger turbine geometries better capture this higher wind speed, and the higher resulting power development counteracts the higher cost of the larger size in the profit objective.

When considering variation in both the power law exponent and the wake decay constant, there is still some turbine migration toward the outer edges of the field, but it is less evident then when considering variation in the power law exponent alone. While the trend in the number of turbines selected for the optimal layout for each atmospheric stability condition remains consistent with the unidirectional case (fewer turbines for unstable conditions, more turbines for stable conditions), where the unidirectional case showed little variation in turbine sizing, the multidirectional case showed significant larger turbine geometries for the unstable case, and with the turbines selecting smaller geometries in more stable atmospheric conditions. This is particularly interesting to note, because due to the inclusion of larger turbines, the objective evaluation and power development for the unstable multidirectional case were significantly better than the objective function evaluation and power development for more stable conditions. For the unidirectional case, it appeared that more stable atmosphere presented ideal wind conditions for both the objective function evaluation and power development, but for the multidirectional case, the more unstable atmospheric conditions are more ideal. This behavior suggests that when multiple, unavoidable wakes are present (as they are in the multidirectional case presented here), unstable atmospheric conditions create the more ideal optimization conditions. The conditions within an unstable wake have a higher relative wake decay constant, meaning the wind speed deficit requires less downstream distance to recover, and the wake itself is wider. The turbines for the unstable case selected larger individual geometries because the wider wake widths preclude them from being able to select smaller turbine geometries in an effort to "get out of the way" of an upstream wake. The larger turbine geometries also inherently develop more power, and capitalize on the unstable conditions' higher wind speed recovery rate within the wake.

\section{CONCLUDING DISCUSSION}

In this work, a collection of modeling advances was employed within an EPS-MAS wind farm optimization algorithm to help approach real-world applicability in resulting turbine layouts and turbine geometries. These models - including an extrapolation of the NREL Wind Cost and Scaling model and means to accommodate both partial wake interaction and wind shear - are explored with variation in atmospheric stability conditions, to better understand how the stability behavior at a particular farm site could affect a potential wind farm layout.

The resulting layouts indicate that for those areas with a narrow angular range of predominant wind directions (similar to the unidirectional scenario), stable atmospheric conditions create higher power 
and higher profit scenarios than either unstable or neutral conditions. These layouts also include a larger number of turbines of mid-range size. For an area with a wider distribution of wind onset angles, such as the multidirectional case shown in this work, the opposite is true - unstable atmospheric conditions lead to higher profit and higher power development. In addition, the unstable multidirectional case layouts included fewer, but significantly larger turbine geometries. Given the variation in resulting layouts when accommodating real-world modeling and the ability to incorporate the atmospheric stability conditions of a potential farm site, this work can inform wind farm developers of the effects of stability on the power development of a wind farm, and can influence the inclusion of these models in real-world farm development.

\section{ACKNOWLEDGEMENTS}

This work has been funded in part by the National Science Foundation under grants CMMI0940730 and CMMI-0855326, and the NREL Research Participant Program.

\section{REFERENCES}

[1] United States Department of Energy. 20\% Wind by 2030: Increasing Wind Energy's Contribution to U.S. Electricity Supply. http://www.nrel.gov/docs/fy08osti/41869.pdf: 2008.

[2] DuPont BL, Cagan J. An Extended Pattern Search Approach to Wind Farm Layout Optimization. ASME J Mech Des 2012;134:1-18. doi:10.1115/1.4006997.

[3] NREL. NREL JEDI Models. Http://www.nrel.gov/analysis/jedi/download.html 2010. http://www.nrel.gov/analysis/jedi/download.html.

[4] Fingersh L, Hand M, Laxson A. Wind Turbine Design Cost and Scaling Model. Golden, CO: National Renewable Energy Laboratory; 2006.

[5] Orsborn S, Cagan J. Multiagent Shape Grammar Implementation: Automatically Generating Form Concepts According to a Preference Function. J Mech Des 2009;131:121007-1 - 121007-10. doi:10.1115/1.4000449.

[6] Mosetti G, Poloni C, Diviacco B. Optimization of wind turbine positioning in large windfarms by means of a genetic algorithm. J Wind Eng Ind Aerodyn 1994;51:105-16. doi:10.1016/01676105(94)90080-9.

[7] Grady SA, Hussaini MY, Abdullah MM. Placement of wind turbines using genetic algorithms. 
Renew Energy 2005;30:259-70. doi:10.1016/j.renene.2004.05.007.

[8] Jensen NO. A Note on Wind Generator Interaction. Roskilde, Denmark: Riso National Laboratory; 1983.

[9] Huang HS. Distributed Genetic Algorithm for Optimization of Wind Farm Annual Profits. 2007 Int Conf Intell Syst Appl to Power Syst 2007:1-6. doi:10.1109/ISAP.2007.4441654.

[10] Huang HS. Efficient hybrid distributed genetic algorithms for wind turbine positioning in large wind farms. 2009 IEEE Int Symp Ind Electron 2009:2196-201. doi:10.1109/ISIE.2009.5213603.

[11] Wang F, Liu D, Zeng L. Study on computational grids in placement of wind turbines using genetic algorithm. 2009 World Non-Grid-Connected Wind Power Energy Conf 2009;2:1-4. doi:10.1109/WNWEC.2009.5335776.

[12] Sisbot S, Turgut O, Tunc M, Camdali U. Optimal Positioning of Wind Turbines on Gokceada Using Multi-Objective Genetic Algorithm. Wind Energy 2009;13:297-306. doi:10.1002/we.

[13] Emami A, Noghreh P. New approach on optimization in placement of wind turbines within wind farm by genetic algorithms. Renew Energy 2010;35:1559-64. doi:10.1016/j.renene.2009.11.026.

[14] Serrano Gonzalez J, Gonzalez Rodriguez AG, Castro Mora J, Riquelme Santos J, Burgos Payan M. Optimization of wind farm turbines layout using an evolutive algorithm. Renew Energy 2010;35:1671-81. doi:10.1016/j.renene.2010.01.010.

[15] Kusiak A, Song Z. Design of wind farm layout for maximum wind energy capture. Renew Energy 2010;35:685-94. doi:10.1016/j.renene.2009.08.019.

[16] Saavedra-Moreno B, Salcedo-Sanz S, Paniagua-Tineo a., Prieto L, Portilla-Figueras a. Seeding evolutionary algorithms with heuristics for optimal wind turbines positioning in wind farms. Renew Energy 2011;36:2838-44. doi:10.1016/j.renene.2011.04.018. 
1 [17] Wan C, Wang J, Yang G, Li X, Zhang X. Optimal micro-siting of wind turbines by genetic algorithms based on improved wind and turbine models. Proc 48h IEEE Conf Decis Control Held Jointly with 2009 28th Chinese Control Conf 2009:5092-6. doi:10.1109/CDC.2009.5399571.

[18] Wan C, Wang J, Yang G, Zhang X. Optimal Micro-siting of Wind Farms by Particle Swarm Optimization. ICSI 2010, 2010, p. 198-205.

[19] Chowdhury S, Zhang J, Messac A, Castillo L. Unrestricted wind farm layout optimization (UWFLO): Investigating key factors influencing the maximum power generation. Renew Energy 2012;38:16-30. doi:10.1016/j.renene.2011.06.033.

[20] Aytun Ozturk U, Norman BA. Heuristic methods for wind energy conversion system positioning. Electr Power Syst Res 2004;70:179-85. doi:10.1016/j.epsr.2003.12.006.

[21] Bilbao M, Alba E. Simulated Annealing for Optimization of Wind Farm Annual Profit. 2009 2nd Int. Symp. Logist. Ind. Informatics, Linz, Australia: Ieee; 2009, p. 1-5. doi:10.1109/LINDI.2009.5258656.

[22] Mustakerov I, Borissova D. Wind turbines type and number choice using combinatorial optimization. Renew Energy 2010;35:1887-94. doi:10.1016/j.renene.2009.12.012.

[23] DuPont BL, Cagan J, Moriarty P. Optimization of Wind Farm Layout and Wind Turbine Geometry Using a Multi-Level Extended Pattern Search Algorithm that Accounts for Variation in Wind Shear Profile Shape. ASME IDETC, vol. In Prepara, Chicago, Illinois, USA: 2012.

[24] Zhang J, Chowdhury S, Messac A, Castillo L, Lebron J. Response Surface Based Cost Model for Onshore Wind Farms Using Extended Radial Basis Functions. ASME Int. Des. Eng. Tech. Conf., Montreal, QC, Canada: 2010, p. 1-16.

[25] Chowdhury S, Messac A, Zhang J, Castillo L, Lebron J. Optimizing the Unrestricted Placement of Turbines of Differing Rotor Diameters in a Wind Farm for Maximum Power Generation. ASME IDETC, Montreal, QC, Canada: 2010, p. 1-16. 
[26] Benatiallah A, Dakyo B. Modelling and Optimisation of Wind Energy Systems. Jordan J Mech Ind Eng 2010;4:143-50.

3

[27] Chen L, Macdonald E. A New Model for Wind Farm Layout Optimization with Landowner Decisions. ASME Int. Des. Eng. Tech. Conf., 2011, p. 1-12.

[28] Kwong WY, Zhang PY, Morgenroth M, Romero D, Amon C, Moran J. Wind Farm Layout Optimization Considering Energy Generation and Noise Propagation. ASME Int. Des. Eng. Tech. Conf., Chicago, Illinois, USA: 2012, p. 1-10.

[29] Chowdhury S, Zhang J, Messac A, Castillo L. Optimizing the arrangement and the selection of turbines for wind farms subject to varying wind conditions. Renew Energy 2013;52:273-82. doi:10.1016/j.renene.2012.10.017.

[30] Larsen GC, Buhl T, Madsen HA, Troldborg N, Larsen TJ, Ott S, et al. TOPFARM - Next Generation Design Tool for Optimisation of Wind Farm Topology and Operation. 2011.

[31] Torczon V, William C, Trosset MW. From Evolutionary Operation to Parallel Direct Search : Pattern Search Algorithms for Numerical Optimization. Comput Sci Stat 1998:396-401.

[32] Yin S, Cagan J. An Extended Pattern Search Algorithm for Three-Dimensional Component Layout. ASME J Mech Des 2000;122:102-8.

[33] Nwana HS. Software Agents : An Overview. Knowl Eng Rev 1996;11:205-44.

[34] Olson J, Cagan J. Interagent ties in team-based computational configuration design. Artif Intell Eng Des Anal Manuf 2004; 18:135-52.

[35] Talukdar S, Baerentzen L, Gove A, Souza P De. Asynchronous Teams: Cooperation Schemes for Autonomous Agents. J Heuristics 1996;4:295-321. 
in a Dynamic Environment. Res Eng Des 1999;11:172-92.

[37] Nii HP. Blackboard Application Systems and a Knowledge Engineering Perspective. AI Mag 1986:82-107.

[38] Nielsen P. Comparing WindPRO and Windfarmer wake loss calculation. EMD Int 2003:1-3.

7

[39] Renkema DJ. Validation of wind turbine wake models. Master's Thesis, Delft University of Technology, 2007.

[40] Katic I, Hojstrup J, Jensen NO. A Simple Model for Cluster Efficiency. Eur. Wind Energy Assoc. Conf. Exhib., Rome, Italy: 1986, p. 407-10.

[41] Rohatgi J, Barbezier GIL. Wind Turbulence and Atmospheric Stability - Their Effect on Wind Turbine Output. Renew Energy 1999;16:908-11.

[42] Hiester TR, Pennell WT. The Meteorological Aspects of Siting Large Wind Turbines. US Dept. of Energy; 1981.

[43] Wharton S, Lundquist JK. Atmospheric Stability Impacts on Power Curves of Tall Wind Turbines - An Analysis of a West Coast North American Wind Farm. Environ Res Lett 2010.

[44] Frandsen S, Antoniou I, Hansen JC, Kristensen L, Chaviaropoulos B, Douvikas D, et al. Redefinition Power Curve for More Accurate Performance Assessment of Wind Farms. Wind Energy 2000;3:81-111.

[45] Irwin. A Theoretical Variation of the Wind Profile Power Law Exponent as a function of Surface Roughness and Stability. Atmos Environ 1979;13:191-4.

[46] Hanafusa T, Lee CB, Lo A. Dependence of the Exponent in Power Law Wind Profiles on Stability and Height Interval. Atmos Environ 1986;20:2059-66. 
[47] Zoumakis NM. The dependence of the power law exponent on surface roughness and stability in a neutrally and stably stratified surface boundary layer.pdf. Atmosfera 1993;6:79-83.

[48] Sumner J, Masson C. Influence of Atmospheric Stability on Wind Turbine Power Performance Curves. J Sol Energy Eng 2006;128:531. doi:10.1115/1.2347714.

[49] Manwell JF, McGowan JG, Rogers AL. Wind Energy Explained: Theory, Design and Application. 2nd Editio. Chichester, UK: John Wiley and Sons; 2009.

10

11 [50] Kelley N, Shirazi M, Jager D, Wilde S, Adams J, Buhl M, et al. Lamar Low-Level Jet Project Interim Report. Golden, CO: 2004.

13

[51] Thomsen K, Sørensen P. Fatigue loads for wind turbines operating in wakes. J Wind Eng Ind Aerodyn 1999;80:121-36. doi:10.1016/S0167-6105(98)00194-9.

16

17

[52] Wharton S, Lundquist JK. Assessing atmospheric stability and its impacts on rotor-disk wind characteristics at an onshore wind farm. Wind Energy 2012;15:525-46. doi:10.1002/we. 


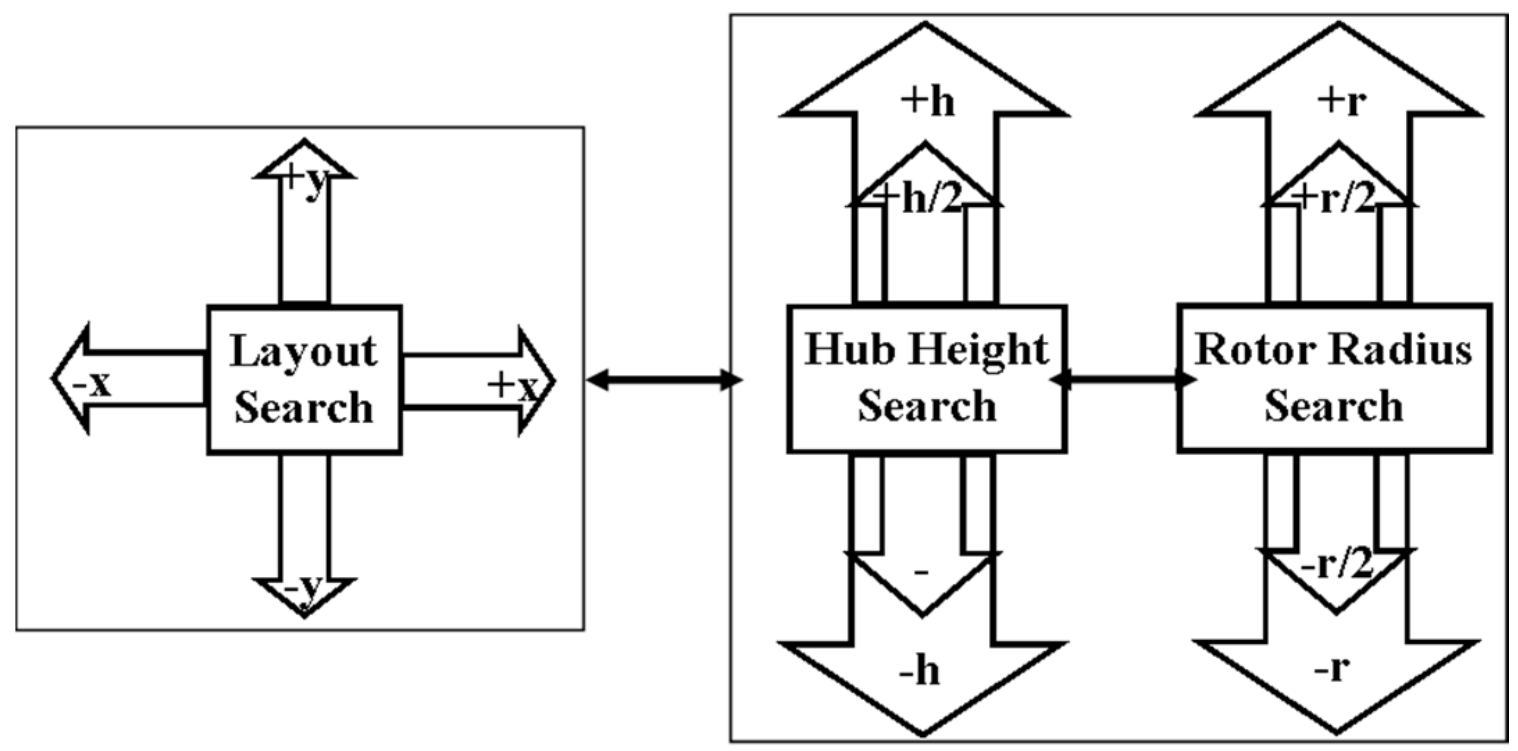

Fig. 1: FLOWCHART FOR MULTI-LEVEL EPS ALGORITHM

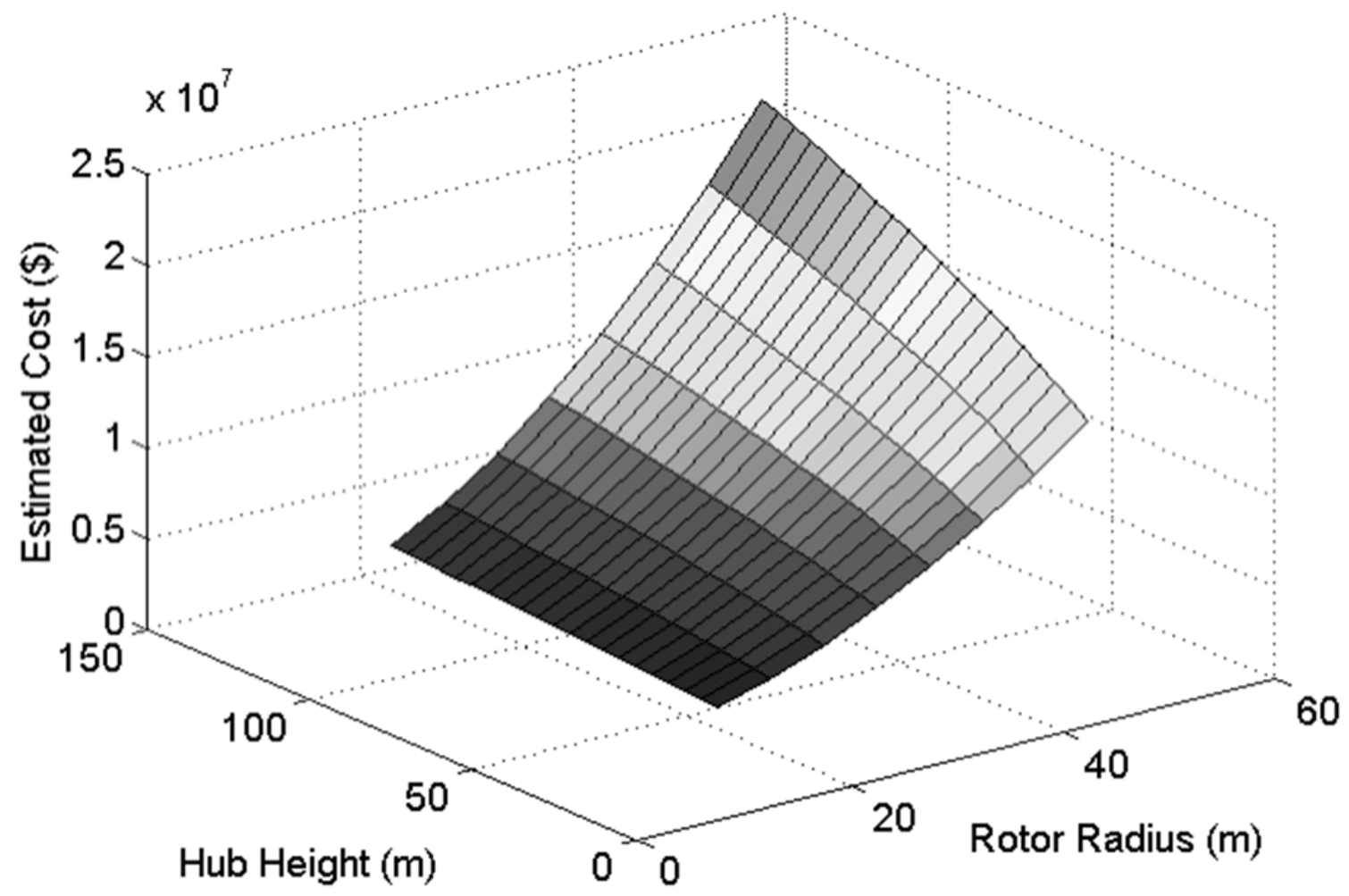

4

Fig. 2: POLYNOMIAL COST SURFACE AS A FUNCTION OF ROTOR RADIUS AND HUB HEIGHT 


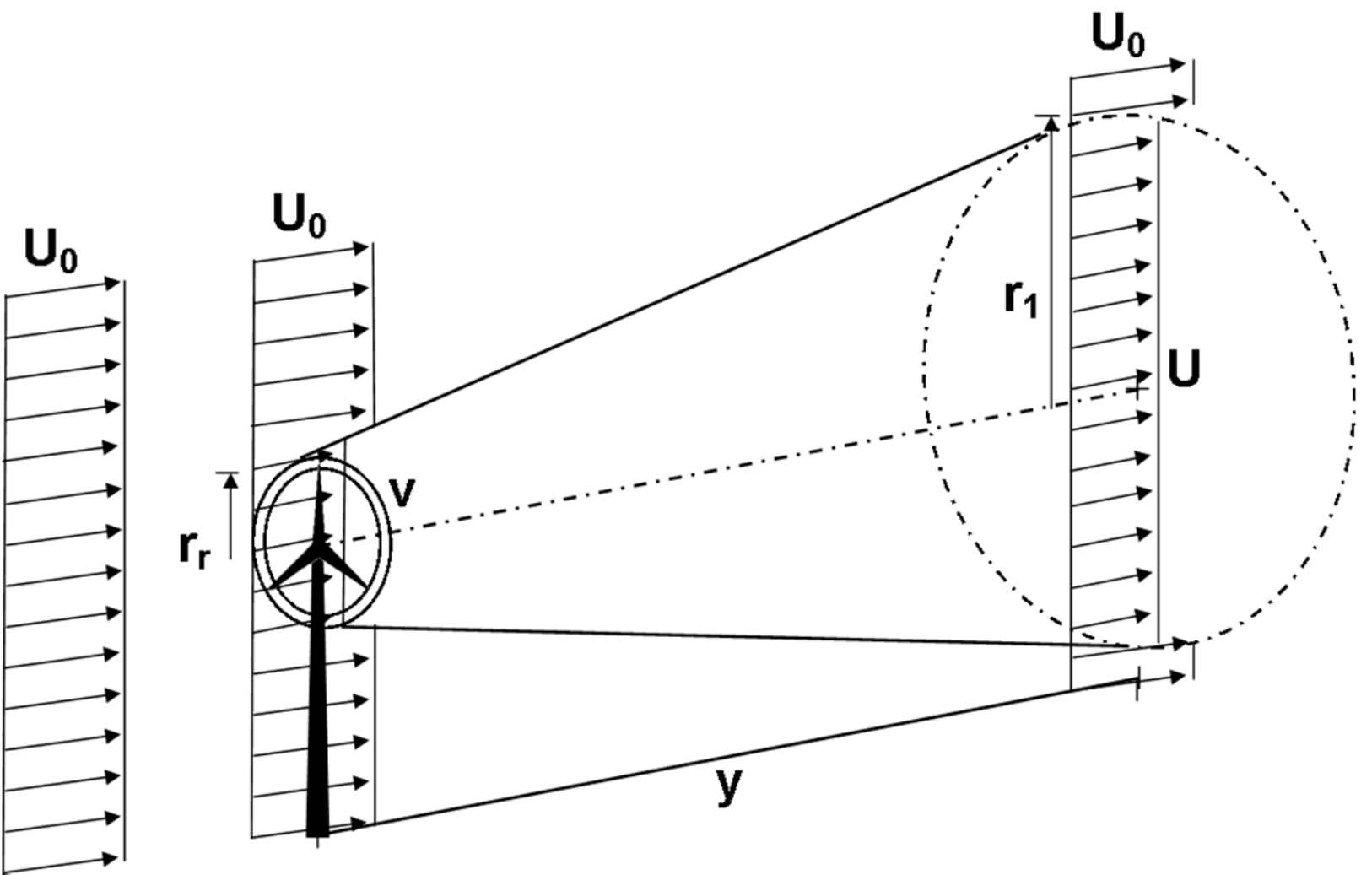

Fig. 3: DEPICTION OF 3-D FRUSTUM SHAPED WAKE

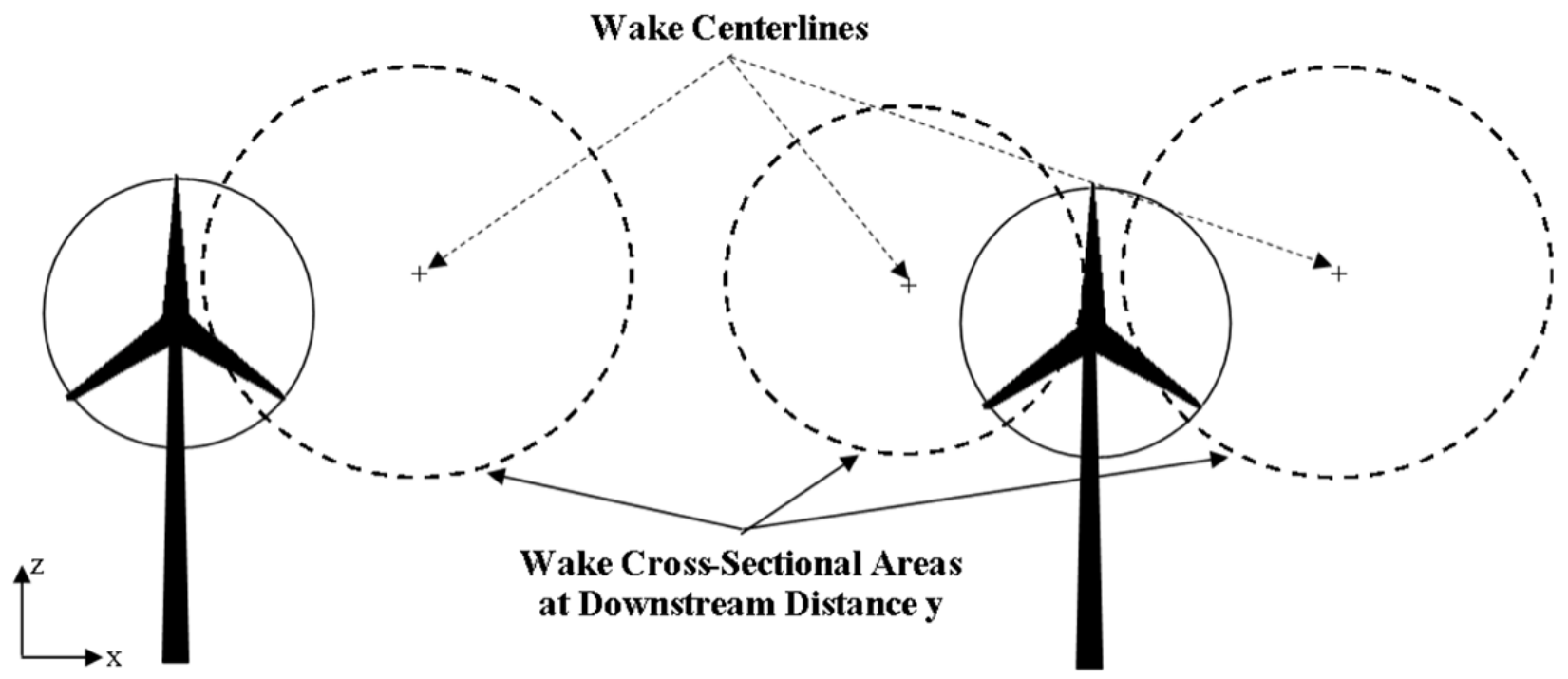

(A)

(B)

Fig. 4: TURBINE WITH PARTIAL WAKE INTERACTION, (A) WITH ONE PARTIAL WAKE, (B) WITH TWO DISTINCT PARTIAL WAKES 


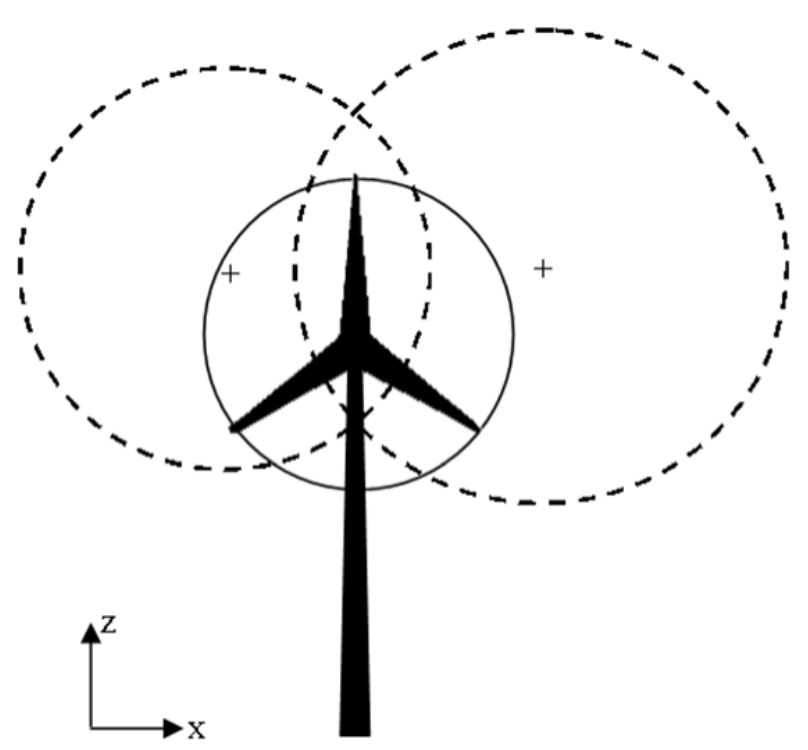

(A)

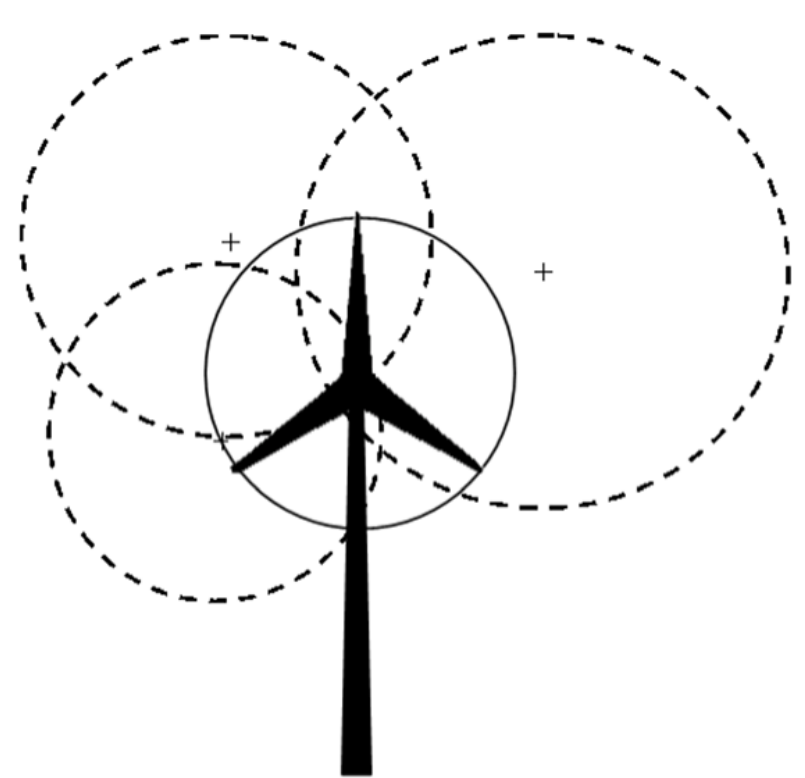

(B)

Fig. 5: TURBINE WITH OVERLAPPING PARTIAL WAKE INTERACTION, (A) WITH TWO WAKES, AND (B) WITH THREE WAKES

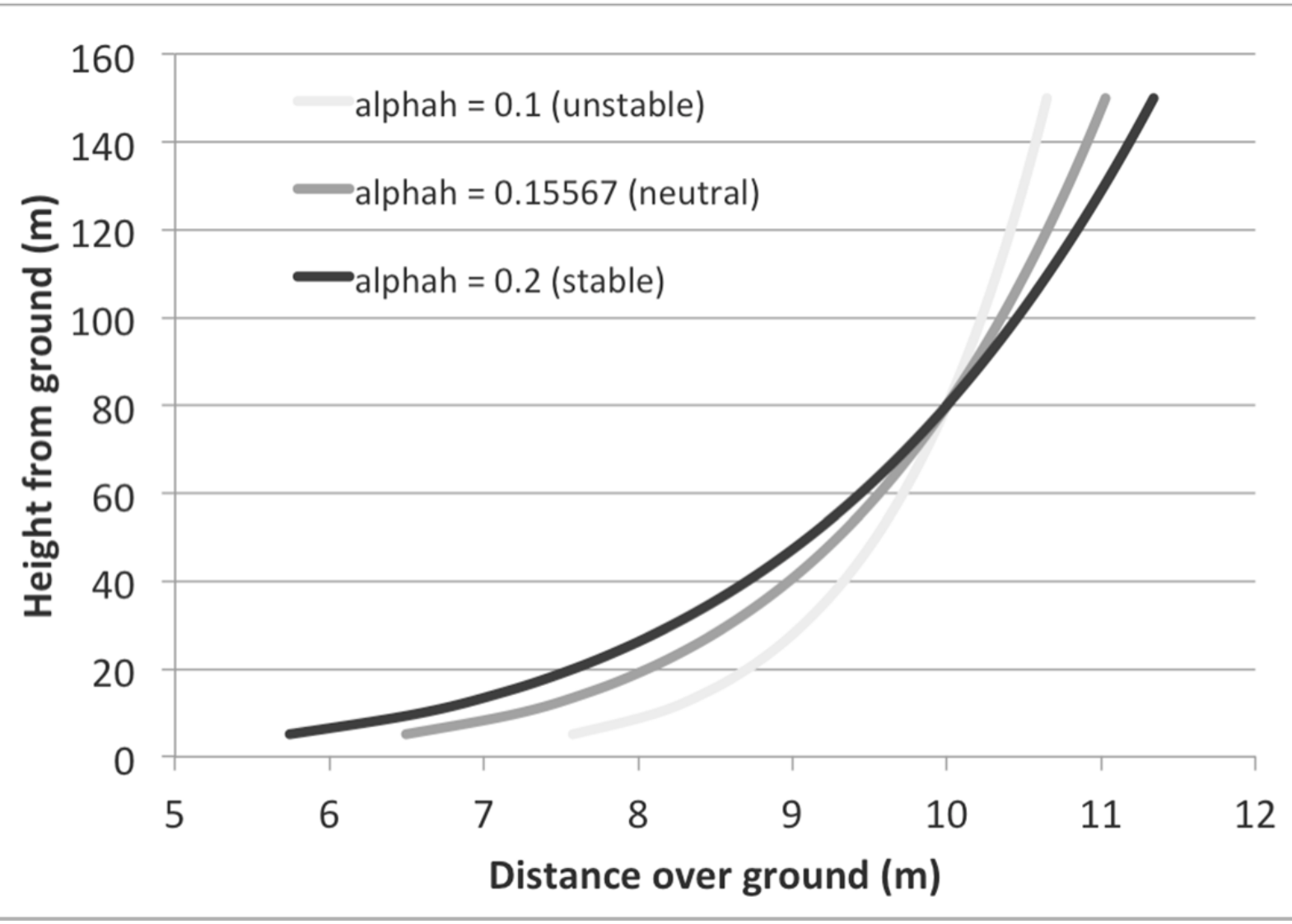

Fig. 6: WIND SHEAR PROFILE SHAPE FOR VARYING ATMOSPHERIC STABILITY CONDITIONS 


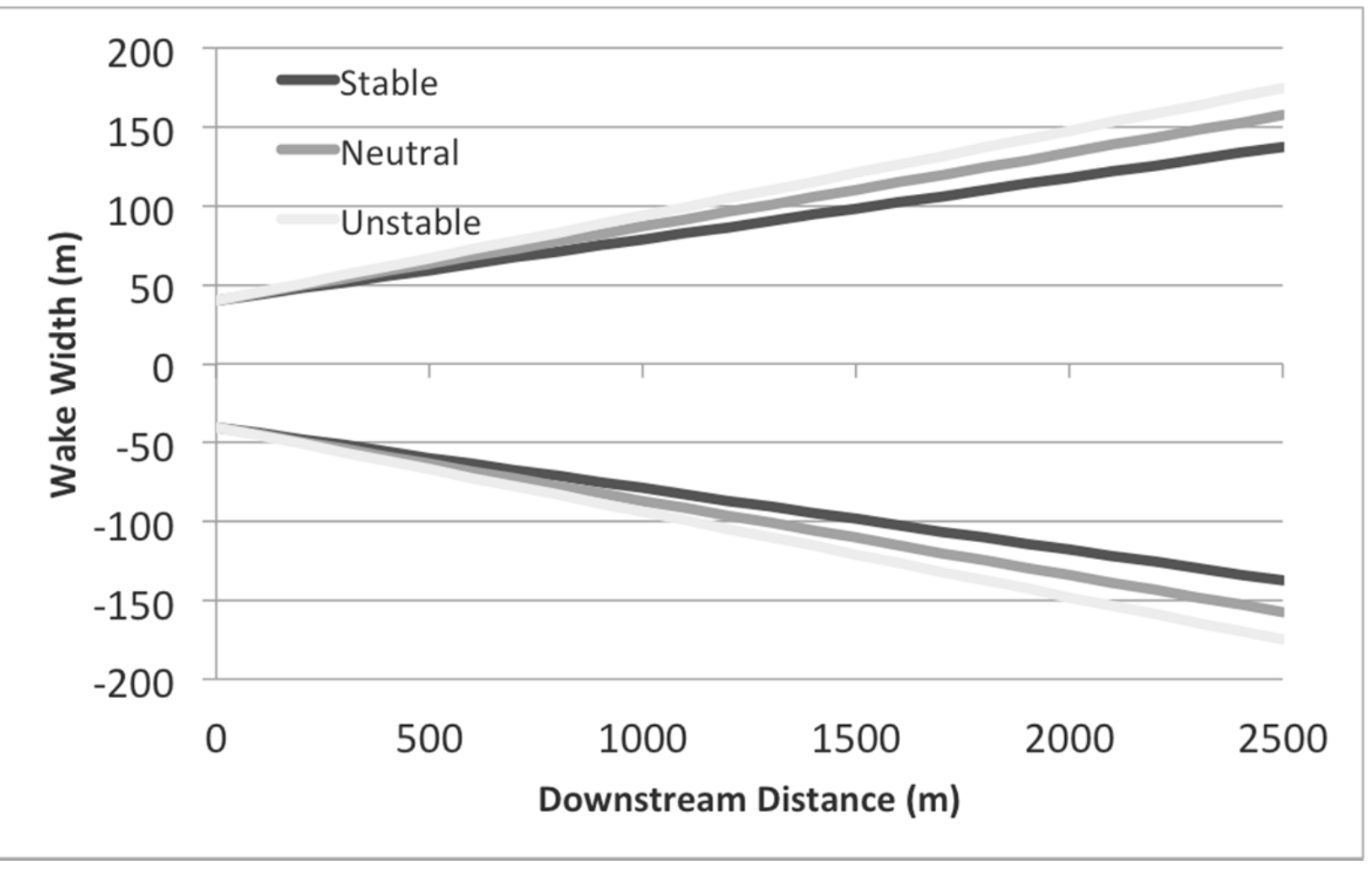

Fig. 7: EFFECT OF ATMOSPHERIC STABILITY ON WAKE WIDTH

4

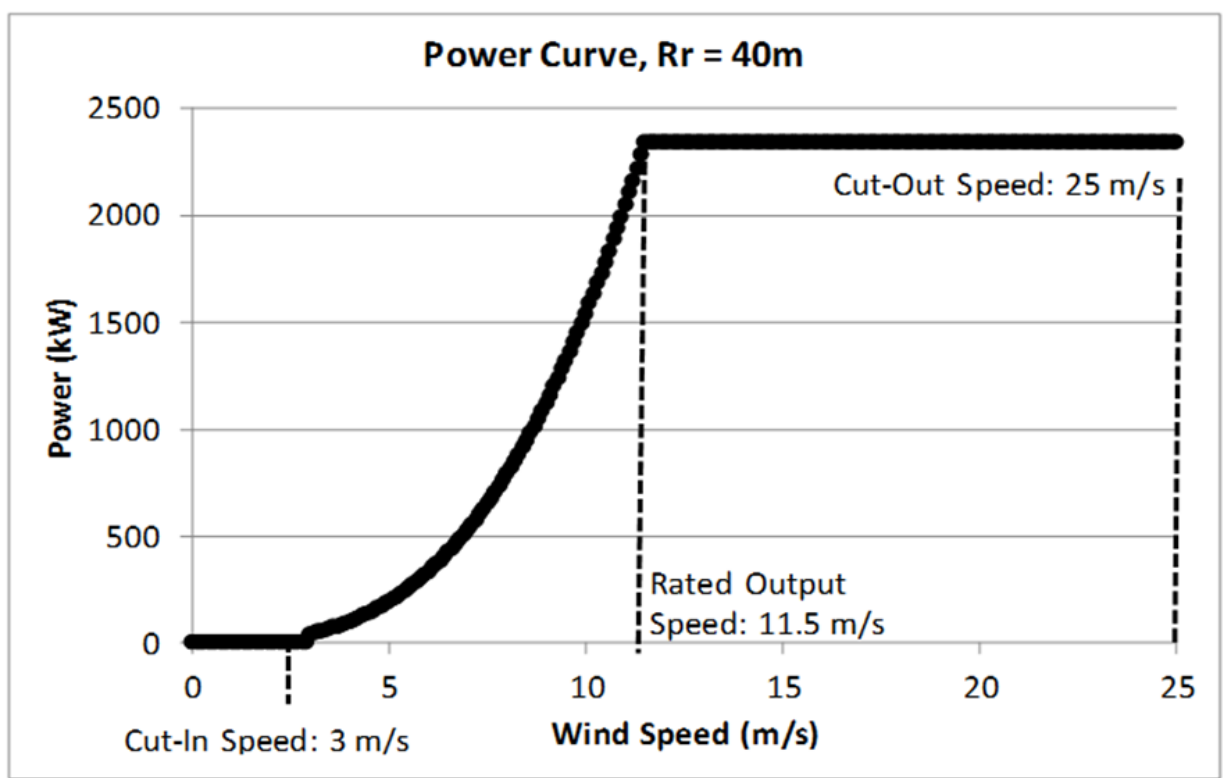

Fig. 8: POWER CURVE: POWER (kW) VERSUS WIND SPEED $(\mathrm{m} / \mathrm{s})$ 

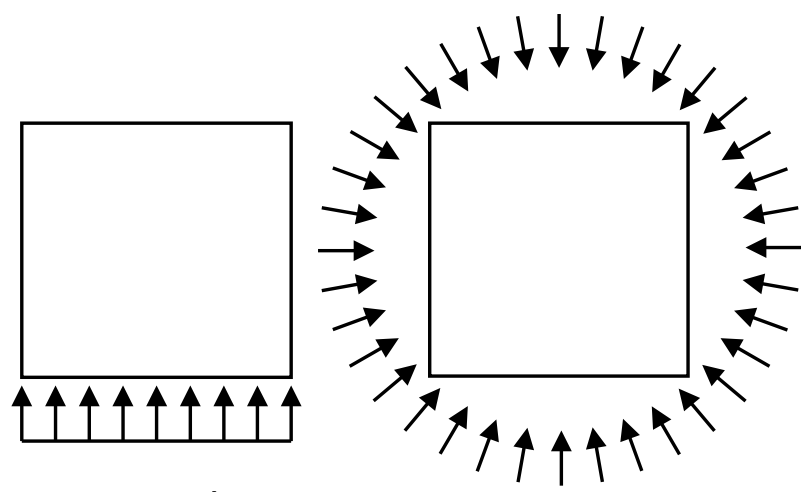

$10 \mathrm{~m} / \mathrm{s}$

All 6, 9, \& $12 \mathrm{~m} / \mathrm{s}$

(a)

(b)

\begin{tabular}{|cccc|}
\hline & Unstable & Neutral & Stable \\
\hline Power Law Exponent $\alpha_{h}$ & 0.1 & 0.15567 & 0.2 \\
Wake Decay Constant $k$ & $0.09759 h^{-0.1352}$ & $0.08835 h^{-0.1521}$ & $0.07535 h^{-0.1496}$ \\
\hline
\end{tabular}

Fig. 9: WIND CASES

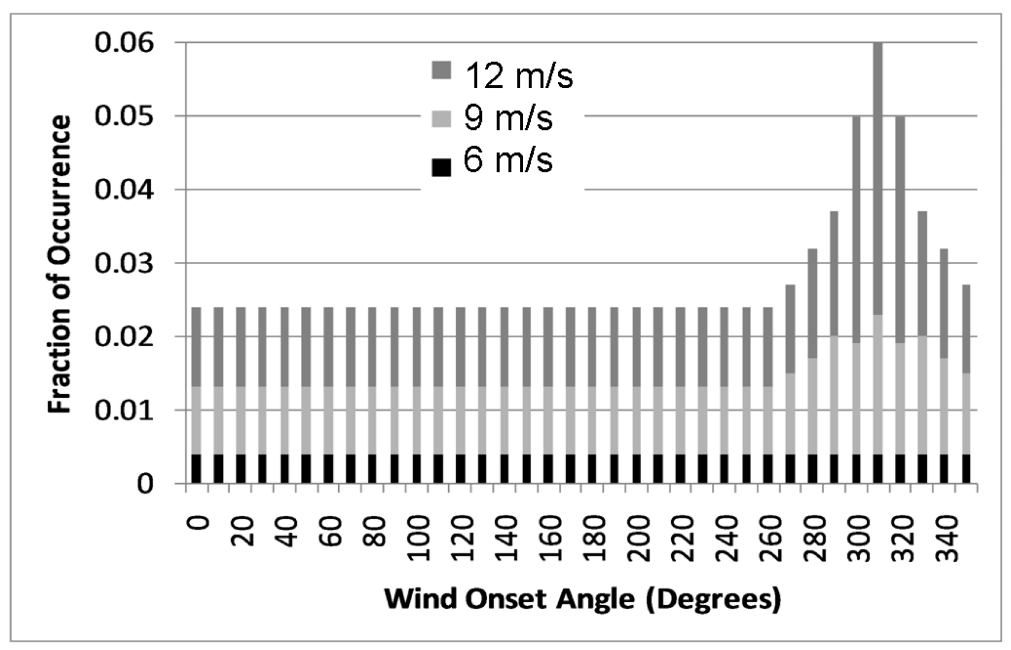

Fig. 10: FRACTION OF OCCURRENCE FOR WIND SPEEDS AND WIND DIRECTIONS - CASE (b)

8 
Table 2: UNIDIRECTIONAL CASE RESULTS, ah ONLY

\begin{tabular}{|cccc|}
\hline & Unstable & Neutral & Stable \\
\hline $\mathrm{N}$ & 38 & 36 & 31 \\
Objective Evaluation & $-3.26156 \mathrm{e}+07$ & $-4.43837 \mathrm{e}+07$ & $-5.83643 \mathrm{e}+07$ \\
Total Power (MW) & 57.6629 & 62.7362 & 79.3729 \\
Avg. Turbine Hub Height (m) & 70.21 & 79.98 & 95.29 \\
Avg. Turbine Rotor Radius (m) & 33.20 & 35.69 & 41.88 \\
\hline
\end{tabular}

3

4

5

6

Table 3: UNIDIRECTIONAL CASE RESULTS, BOTH ah \& $k$

\begin{tabular}{|cccc|}
\hline & Unstable & Neutral & Stable \\
\hline $\mathrm{N}$ & 39 & 40 & 42 \\
Objective Evaluation & $-3.74301 \mathrm{e}+07$ & $-5.18889 \mathrm{e}+07$ & $-5.43761 \mathrm{e}+07$ \\
Total Power (MW) & 65.1655 & 75.1603 & 77.8055 \\
Avg. Turbine Hub Height (m) & 75.15 & 77.28 & 74.93 \\
Avg. Turbine Rotor Radius (m) & 34.83 & 35.69 & 34.87 \\
\hline
\end{tabular}

\begin{tabular}{|lll} 
Hub Height $(\mathrm{m})$ & Rotor Radius $(\mathrm{m})$ \\
$38-59$ & I & $19-29$ \\
$60-79$ & II & $30-39$ \\
$80-120$ & III & $40-59$ \\
$>120$ & IV & $>60$
\end{tabular}

Fig. 11: KEY FOR TURBINE SIZES

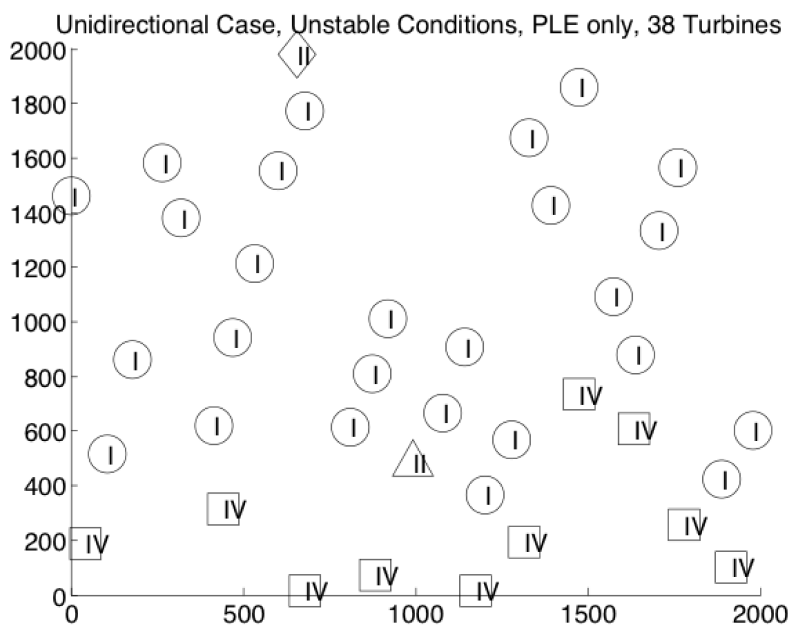

(a)

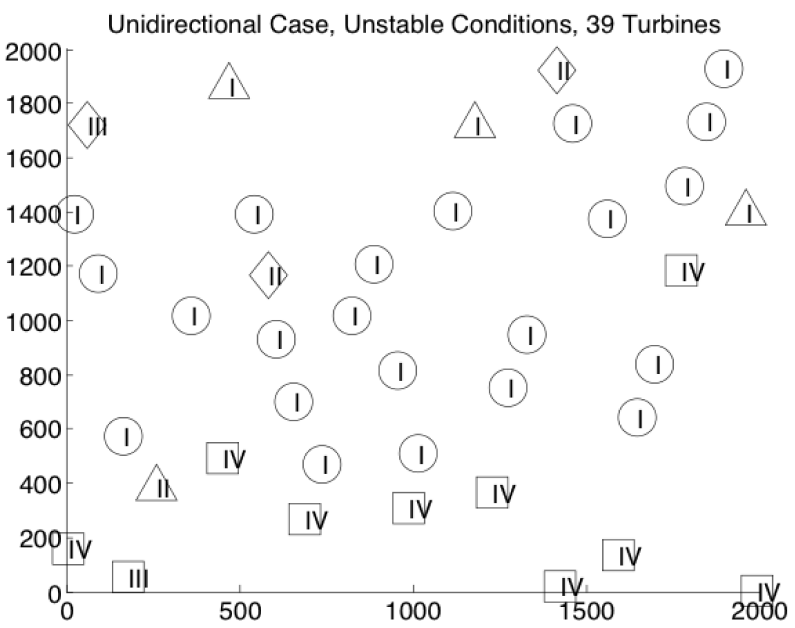

(b)

Fig. 12: UNIDIRECTIONAL CASE, UNSTABLE: (a) ah ONLY, 38 TURBINES, AND (b) BOTH ah AND $k, 39$ TURBINES 


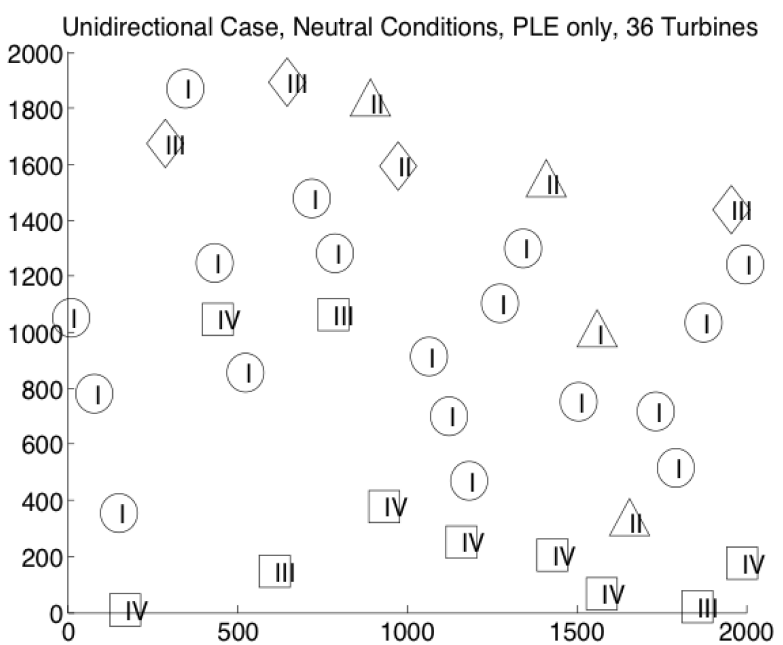

(a)

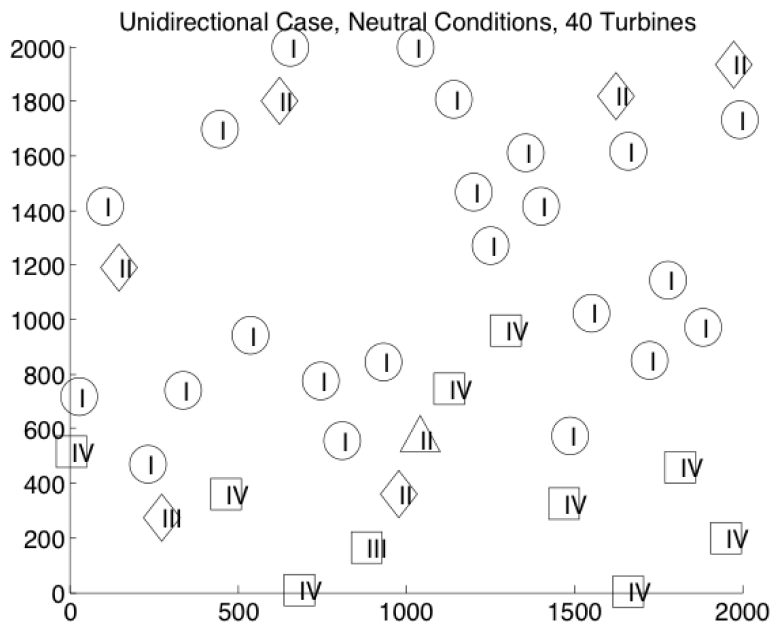

(b)

Fig. 13: UNIDIRECTIONAL CASE, NEUTRAL: (a) ah ONLY, 36 TURBINES, and (b) BOTH ah \& $k, 40$ TURBINES

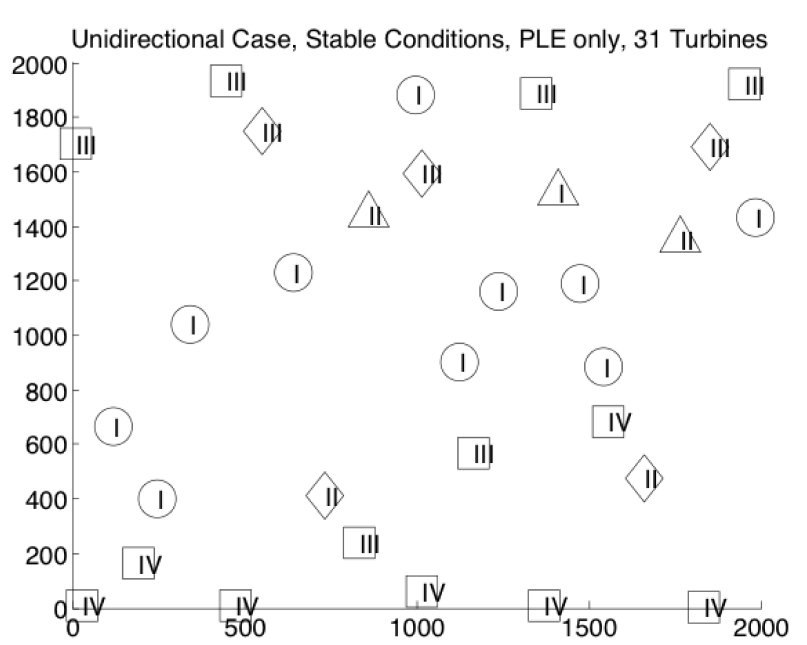

(a)

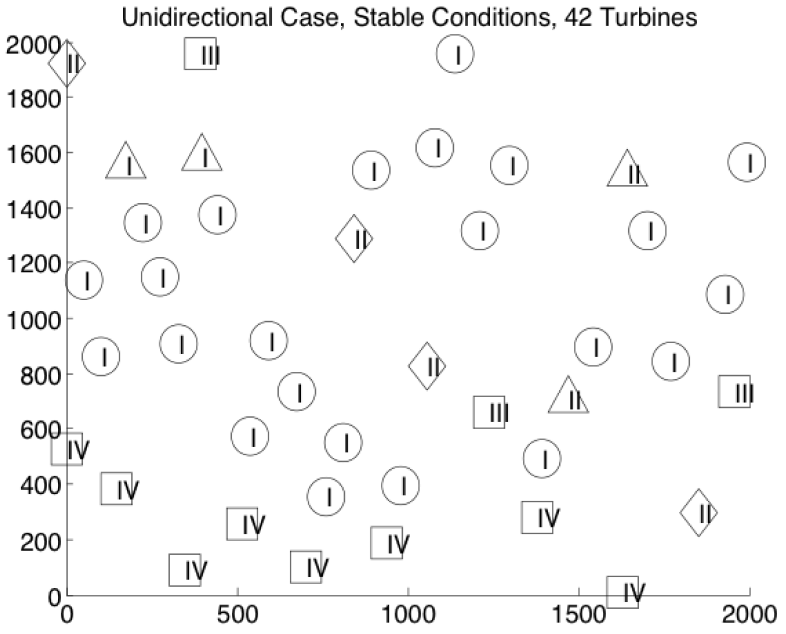

(b)

Fig. 14: UNIDIRECTIONAL CASE, STABLE: (a) ah ONLY, 31 TURBINES, and (b) BOTH ah \& k, 42 TURBINES

Table 4: MULTIDIRECTIONAL CASE RESULTS, ah ONLY

\begin{tabular}{|cccc|}
\hline & Unstable & Neutral & Stable \\
\hline $\mathrm{N}$ & 8 & 9 & 8 \\
Objective Evaluation & $-5.74532 \mathrm{e}+06$ & $-6.90359 \mathrm{e}+06$ & $-7.24115 \mathrm{e}+06$ \\
Total Power (MW) & 9.92175 & 12.4051 & 12.5599 \\
Avg. Turbine Hub Height (m) & 75.87 & 78.36 & 80.00 \\
Avg. Turbine Rotor Radius (m) & 35.03 & 37.26 & 40.00 \\
\hline
\end{tabular}


Table 5: MULTIDIRECTIONAL CASE RESULTS, BOTH ah \& k

\begin{tabular}{|cccc|}
\hline & Unstable & Neutral & Stable \\
\hline $\mathrm{N}$ & 17 & 21 & 24 \\
Objective Evaluation & $-8.95028 \mathrm{e}+07$ & $-7.49638 \mathrm{e}+07$ & $-7.2379 \mathrm{e}+07$ \\
Total Power (MW) & 75.7309 & 60.5494 & 48.7015 \\
Avg. Turbine Hub Height (m) & 116.65 & 94.20 & 81.41 \\
Avg. Turbine Rotor Radius (m) & 58.03 & 46.82 & 40.63 \\
\hline
\end{tabular}

3

4

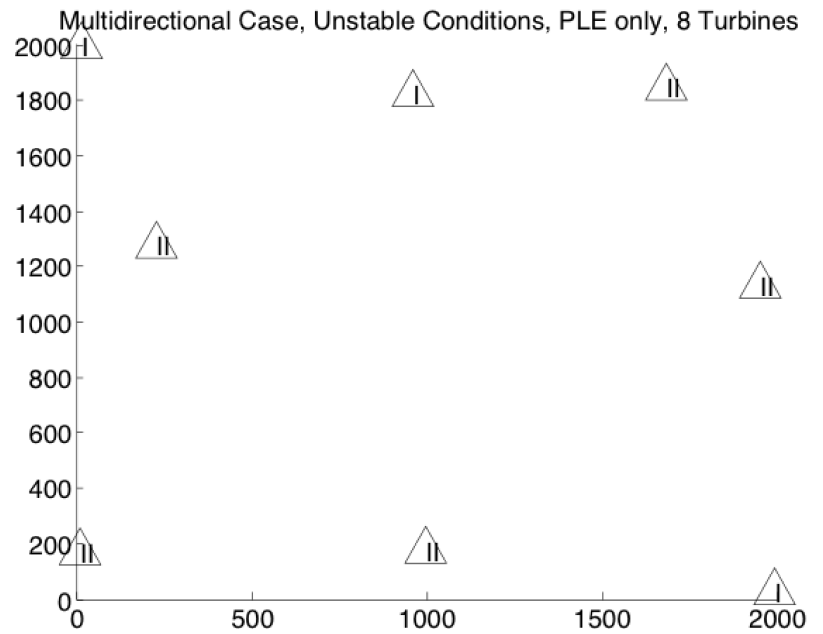

(a)

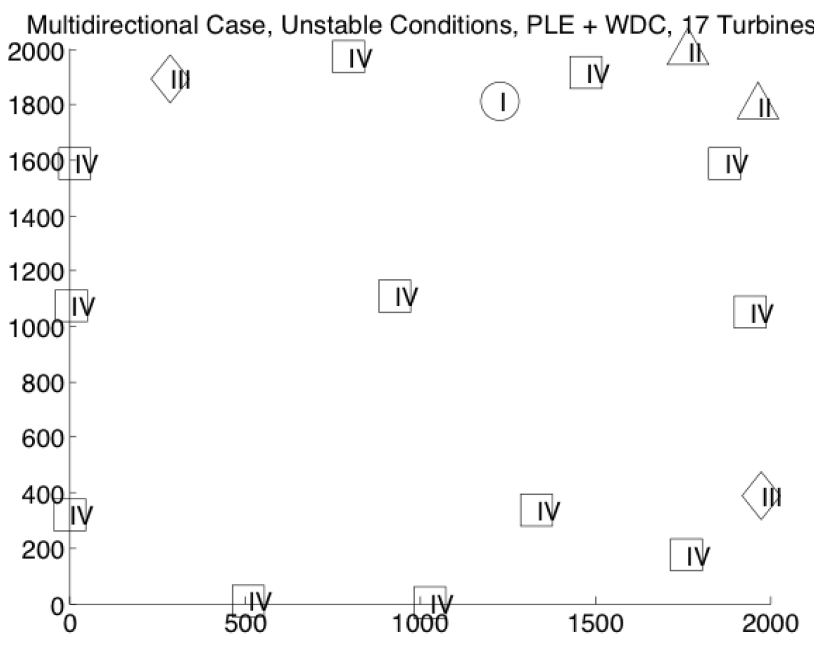

(b)
5

Fig. 15: MULTIDIRECTIONAL CASE, UNSTABLE (ah ONLY), (a) ah ONLY, 8 TURBINES, and (b) BOTH ah \& $\mathrm{k}, 17$ TURBINES 
Multidirectional Case, Neutral Conditions, PLE only, 9 Turbines

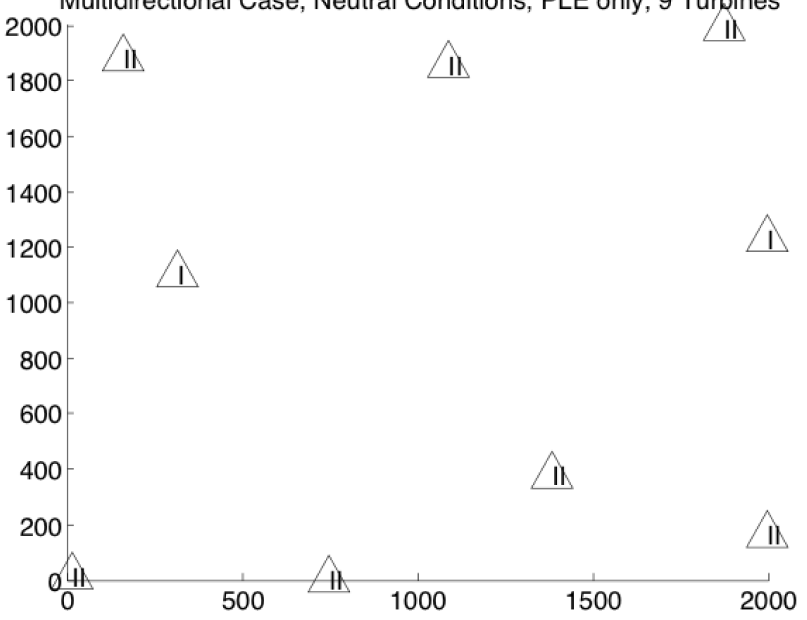

(a)

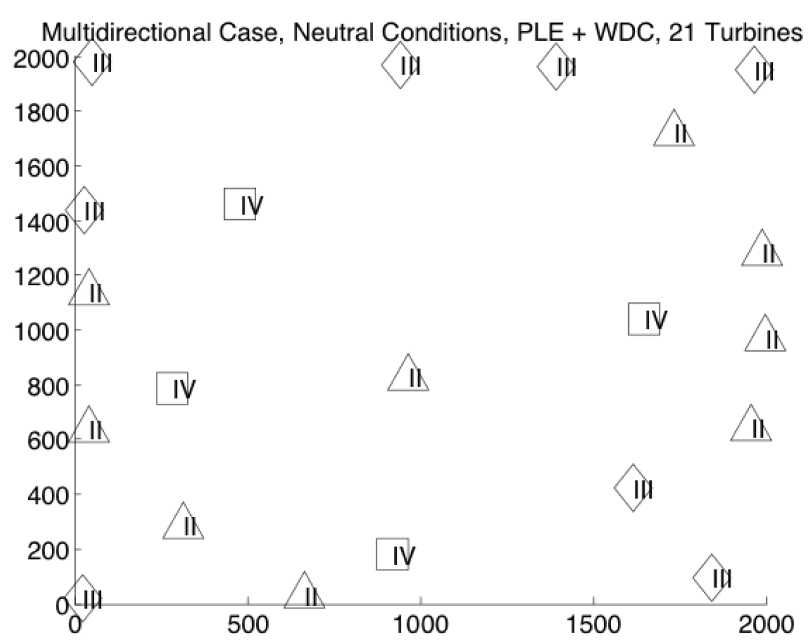

(b)

Fig. 16: MULTIDIRECTIONAL CASE, NEUTRAL (ah ONLY), (a) ah ONLY, 9 TURBINES, and (b) BOTH ah \& $k, 21$ TURBINES

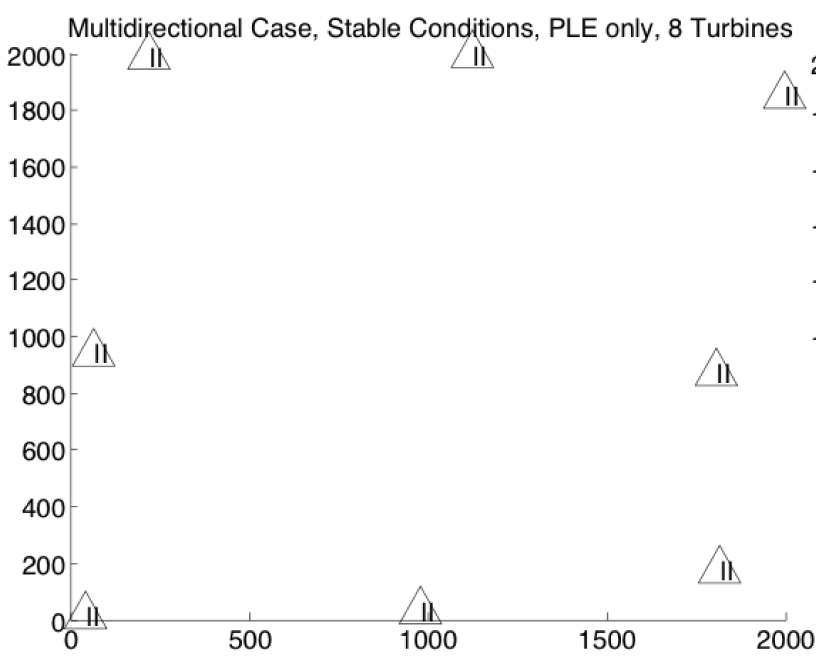

(a)
Multidirectional Case, Stable Conditions, PLE + WDC, 24 Turbines II. 2000 -11 III II II II 1600 - in $1400-11$ 1200 1000 Al IIII Al
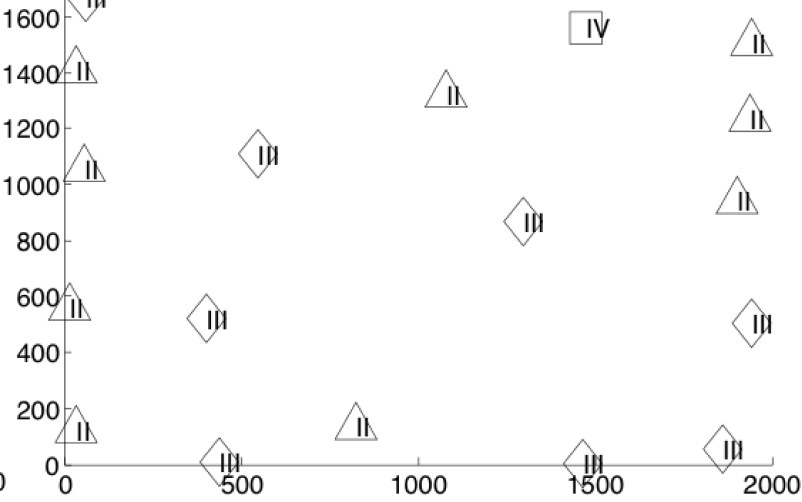

(b)

Fig.17: MULTIDIRECTIONAL CASE, STABLE (ah ONLY), (a) ah ONLY, 8 TURBINES, and (b) BOTH ah \& k, 24 TURBINES 